\title{
Horizontal dynamic stiffness and interaction factors of inclined piles
}

DOI:

10.1061/(ASCE)GM.1943-5622.0000966

\section{Document Version}

Accepted author manuscript

Link to publication record in Manchester Research Explorer

\section{Citation for published version (APA):}

Wang, J., Zhou, D., Ji, T., \& Wang, S. (2017). Horizontal dynamic stiffness and interaction factors of inclined piles. International Journal of Geomechanics, 17(9), [04017075]. https://doi.org/10.1061/(ASCE)GM.1943-5622.0000966

\section{Published in:}

International Journal of Geomechanics

\section{Citing this paper}

Please note that where the full-text provided on Manchester Research Explorer is the Author Accepted Manuscript or Proof version this may differ from the final Published version. If citing, it is advised that you check and use the publisher's definitive version.

\section{General rights}

Copyright and moral rights for the publications made accessible in the Research Explorer are retained by the authors and/or other copyright owners and it is a condition of accessing publications that users recognise and abide by the legal requirements associated with these rights.

\section{Takedown policy}

If you believe that this document breaches copyright please refer to the University of Manchester's Takedown Procedures [http://man.ac.uk/04Y6Bo] or contact uml.scholarlycommunications@manchester.ac.uk providing relevant details, so we can investigate your claim.

\section{OPEN ACCESS}


Jue Wang, Ph.D., College of Civil Engineering, Nanjing Tech University, Nanjing 211816, China; College of Mechanical \& Electrical Engineering, Hohai University, Changzhou, China.

Ding Zhou*, Ph.D., College of Civil Engineering, Nanjing Tech University, Nanjing 211816, China.

Tianjian Ji, Ph.D., School of Mechanical, Aerospace and Civil Engineering, The University of Manchester, Manchester, M13 9PL, UK.

Shuguang Wang, Ph.D., College of Civil Engineering, Nanjing Tech University, Nanjing 211816, China.

\section{Abstract:}

A Timoshenko beam-on-Pasternak-foundation model (T-P) model is developed to estimate the horizontal dynamic impedance and interaction factors for inclined piles subjected to a horizontal harmonic load. The inclined pile with a fixed pile-to-cap connection is modeled as a Timoshenko beams embedded in the homogeneous Pasternak foundation. The reactions of the soil on the pile tip are simulated by three springs in parallel with corresponding dashpots. The differential equations of normal and axial vibrations of the inclined pile are solved by means of the initial parameter method. The model and the theoretical derivation are validated through comparisons with results from other theoretical models for some large-diameter end-bearing piles and inclined piles. The effects of shear deformations of the soil and inclined piles, during the vibration, are highlighted by comparing the results between the T-P model and the Euler beam-on-dynamic-Winkler-foundation (E-W) model. It is indicated that the T-P Model is more accurate for analyzing the dynamic performance of the inclined piles with small slenderness ratios and large inclined angles. The effects of the inclined angle, slenderness ratio and distance-diameter ratio on the dynamic impedance and interaction factors are studied by numerical examples. It is demonstrated that the increased angle of the pile results in an increase of horizontal impedance and decreases of interaction factors.

\section{Keywords:}

Soil-structure interaction; Inclined pile; Pile impedance; Interaction factor; Timoshenko beam;

Pasternak foundation.

\section{Introduction}

Inclined piles were once considered to be detrimental for their seismic behavior (Deng et al. 2007; 
Poulos 2006) and even recommended being avoided by some codes (AFPS 1990; CEN 2004) due to their poor performances in a series of earthquakes occurred in the 1990s. However, numerical (Gerolymos et al. 2008; Turan et al. 2013; Sadek and Isam 2004) and experimental studies (Okawa et al. 2002; Gotman 2013) showed the advantages of the inclined piles. The ultimate reasons of failures may be due to the incorrect design and construction techniques rather than the pile inclination itself. As inclined piles can transmit the applied horizontal loads partly through axial compression, they provide larger horizontal stiffness and bearing capacity than conventional vertical piles. Therefore, employing inclined piles in foundations for buildings, bridges and marginal wharfs is an efficient way to resist horizontal loads such as seismic waves, vehicle impacts and ocean waves (Gazetas and Mylonakis 1998; Padrón et al. 2010). Inclined angles commonly used in practice are between $5^{\circ}-15^{\circ}$, in addition to the less usual cases between $20^{\circ}$ and $25^{\circ}$.

Padron et al. (2010, 2012, 2014) investigated dynamic impedances of both single inclined pile and group inclined piles, as well as the kinematic interaction factors between adjacent inclined piles, using a boundary element-finite element coupling model (BEM-FEM). In their study, the pile is modeled as an elastic compressible Euler-Bernoulli beam. Their investigation contributed an understanding of the effect of inclined piles on the dynamic impedances of deep foundations. Recently, they further studied the response of the structure supported by an inclined pile foundation (Medina et al. 2015). In addition to numerical methods, some simplified analytical models are also applied in the analysis of soil-pile dynamic interaction. Makris and Gazetas (1992) presented a Euler Beam-on-dynamic-Winkler-foundation (E-W) model to account for the impedance of a single vertical pile and interaction factors between adjacent vertical piles, which can be extended to evaluate the effect of dynamic pile groups using the superposition method (Kaynia and Kausel 1982). Mylonakis and Gazetas $(1998,1999)$ used the E-W model to determine the dynamic interaction factors for axial and lateral vibrations of vertical piles in layered soil by considering the presence of receiver piles. Subsequently, the E-W model has received a widespread application due to low computational complexity and reasonable agreement with the rigorous solutions (Liu et al. 2014; Sica et al. 2011). Gerolymos and Gazetas (2006) developed a multi-Winkler model to analyse the static and dynamic stiffness of rigid caisson foundations with small slenderness ratio. In recent years, some researchers have managed to extend the E-W model to the dynamics of inclined piles. Ghasemzadeh and Alibeikloo (2011) used the Euler beam-on-dynamic-Winkler-foundation (E-W) 
model to analyse the interaction factor between two infinitely long inclined piles. As the limitation of the theoretical assumptions, the E-W model only valid for those piles with large slenderness ratio (Yokoyama, 1996; Wang et al., 2014a). Ghazavi et al. (2013) further considered the dynamic interaction factor of adjacent inclined piles under oblique harmonic loads.

However, the E-W model neglects the shear deformations of both soil medium and the pile, which is only valid for the piles with a large slenderness ratio (i.e. piles with large diameter and/or short length). Actually, piles with small slenderness ratios are commonly used on the firm stratum to support superstructures (Mylonakis 2001). Kampitsis et al. (2013) demonstrated the advantages of Timoshenko theory on the kinematic and inertial interaction between soil and column-pile with a small slenderness ratio. Recently, Wang et al. (2014a, 2014b) presented a Timoshenko beam-on-Pasternak-foundation (T-P) model to determine the dynamic interaction factors between vertical short piles with hinged-head connection in the multilayered soil medium. The parametric studies confirmed that the T-P model subjected to high frequency excitation provided the improved results for the dynamic interaction of piles with small slenderness ratio.

As an extension of previous works (Wang et al. 2014a, 2014b), the T-P model is further applied to analyzing the impedance of single inclined pile and dynamic interaction factors between adjacent inclined piles. The shear deformation and rotational inertia of inclined piles, as well as the shear deformation of soil, have been simultaneously considered to overcome the limitation of conventional E-W model (Ghasemzadeh and Aleikloo, 2011). Transformation between the local and global coordinate systems is used in the analysis as the inclined piles can transmit the horizontal loads not only through the bending deformation but also through the axial deformation. Therefore, the horizontal and vertical interaction factors for inclined piles are coupled. The effects of slenderness ratios, pile-soil modulus ratios, the inclined angles of single pile on adjacent piles have been studied in detail.

\section{Model description}

Fig. 1 shows a cylindrical elastic pile embedded in a homogeneous half-space with an inclined angle $\varphi$. The head of the pile is fixed to the cap. To conveniently evaluate the dynamic impedance atop the head of the inclined pile, a horizontal harmonic excitation $H \mathrm{e}^{\mathrm{i} \omega t}$ in the global coordinate system $(x-z)$ 
is decomposed into an axial component $Q \mathrm{e}^{\mathrm{i} \omega t}$ and a normal component $P \mathrm{e}^{\mathrm{i} \omega t}$ in a local coordinate system ( $\left.x^{\prime}-z^{\prime}\right)$. Here, $H, Q$ and $P$ are the load amplitudes, $\omega$ denotes the frequency of the external

$g_{x} \cong 0.5 k_{x}$.

in which, $E_{\mathrm{s}}, G_{\mathrm{s}}, v_{\mathrm{s}}, \rho_{\mathrm{s}}, \beta_{\mathrm{s}}$ and $V_{\mathrm{s}}$ are the Young's modulus, shear modulus, Poisson's ratio, mass density, damping and shear wave velocity of the soil medium, respectively; $L$ and $d$ are the length and sectional diameter of the inclined pile, respectively. $a_{0}=\omega d / V_{s}$ is the dimensionless frequency.

As axial vibration of the pile does not induce the shear deformation and rotational inertia, the coefficients of springs and dashpots based on the Novak's plain strain model (Novak and Aboul-Ella 1978) are given as follows:

$$
k_{z} \cong 2 \pi a_{0} G_{s} \frac{\mathrm{J}_{1}\left(a_{0}\right) \mathrm{J}_{0}\left(a_{0}\right)+\mathrm{Y}_{1}\left(a_{0}\right) \mathrm{Y}_{0}\left(a_{0}\right)}{\mathrm{J}_{0}^{2}\left(a_{0}\right)+\mathrm{Y}_{0}^{2}\left(a_{0}\right)}
$$

in which, $\mathbf{J}_{0}$ and $\mathrm{J}_{1}$ are the first kind of Bessel function of the zero-order and the first-order, 
respectively; $\mathrm{Y}_{0}$ and $\mathrm{Y}_{1}$ are the second kind of Bessel function of the zero-order and the first-order, respectively.

It is well known that the mechanical properties at the pile head is unaffected by the boundary condition at the pile tip for the case with a large slenderness ratio $L / d$. However, different from the infinite long pile, the reaction of the soil on the pile tip should be considered when it has a small slenderness ratio $(L / d<10)$ (Gerolymos and Gazetas 2006). The analytical expressions for normal, axial and rotational springs in parallel with dashpots at the pile tip are suggested by Novak and Sacks (1973) as follows:

$$
\left[\boldsymbol{K}_{\mathrm{tip}}^{x}\right]=\left[\begin{array}{cc}
\left(4.3+\mathrm{i} 2.7 a_{0}\right) G_{\mathrm{s}, \mathrm{tip}}(d / 2) & 0 \\
0 & \left(2.5+\mathrm{i} 0.43 a_{0}\right) G_{\mathrm{s}, \mathrm{tip}}(d / 2)^{3}
\end{array}\right]
$$

$K_{\text {tip }}^{z}=(7.5+\mathrm{i} 3.4) G_{\mathrm{s}, \mathrm{tip}}(d / 2)$.

\section{Formulation}

\section{Normal vibration of an inclined pile}

For simplifying the analysis, the displacement of the inclined pile subjected to horizontal harmonic excitation is decomposed into a normal component and an axial component in a local coordinate system. The horizontal impedance of the inclined pile can be finally obtained using the superposition method. As expected, the formulation in all steps are valid for vertical piles when $\varphi_{1}=0$.

By using the Hamilton principle and the Timoshenko beam theory, the governing differential equations for the translational and the rotational vibrations of a loaded pile are given by

$\rho_{p} A_{p} \frac{\partial^{2} u_{\mathrm{a}}\left(z^{\prime}, t\right)}{\partial t^{2}}=-\frac{\partial}{\partial z^{\prime}}\left[\kappa G_{p} A_{p}\left(\theta_{a}\left(z^{\prime}, t\right)-\frac{\partial u_{\mathrm{a}}\left(z^{\prime}, t\right)}{\partial z^{\prime}}\right)\right]-\left(k_{x} u_{\mathrm{a}}\left(z^{\prime}, t\right)-g_{x} \frac{\partial^{2} u_{\mathrm{a}}\left(z^{\prime}, t\right)}{\partial z^{\prime 2}}+c_{x} \frac{\partial u_{\mathrm{a}}\left(z^{\prime}, t\right)}{\partial t}\right)$

$\rho_{p} I_{p} \frac{\partial^{2} \theta_{\mathrm{a}}\left(z^{\prime}, t\right)}{\partial t^{2}}=E_{p} I_{p} \frac{\partial^{2} \theta_{\mathrm{a}}\left(z^{\prime}, t\right)}{\partial z^{\prime 2}}-\kappa G_{p} A_{p}\left(\theta_{\mathrm{a}}\left(z^{\prime}, t\right)-\frac{\partial u_{\mathrm{a}}\left(z^{\prime}, t\right)}{\partial z^{\prime}}\right)$

where $v_{\mathrm{p}}, \rho_{\mathrm{p}}, E_{\mathrm{p}}$ and $G_{\mathrm{p}}$ are the Poisson's ratio, mass density, Young's modulus, shear modulus of the pile, respectively; $A_{\mathrm{p}}, I_{\mathrm{p}}$ and $\kappa=6\left(1+v_{\mathrm{p}}\right) /\left(7+6 v_{\mathrm{p}}\right)$ are the area of cross section, inertia moment and shear coefficient of the pile, respectively. $u_{\mathrm{a}}$ and $\theta_{\mathrm{a}}$, the normal displacement and bending rotation of the pile, should experience harmonic movements, $u_{\mathrm{a}}\left(z^{\prime}, t\right)=U_{\mathrm{a}}\left(z^{\prime}\right) \mathrm{e}^{\mathrm{i} \omega t}$ and $\theta_{\mathrm{a}}\left(z^{\prime}, t\right)=\Theta_{\mathrm{a}}\left(z^{\prime}\right) \mathrm{e}^{\mathrm{i} \omega t}$ as the system is subjected to a harmonic action. Applying the differentiation chain rule on Eq. (4) and 
141 Eq. (5), the differential equations of normal vibration and the flexural rotational vibration can be expressed as

$\frac{d^{4} U_{\mathrm{a}}}{d z^{14}}+\frac{E_{p} I_{p} K_{p}-J_{p} g_{x}+S_{p}\left(J_{p}+g_{x}\right)}{E_{p} I_{p}\left(J_{p}+g_{x}\right)} \frac{d^{2} U_{\mathrm{a}}}{d z^{\prime 2}}-\frac{K_{p}\left(J_{p}-S_{p}\right)}{E_{p} I_{p}\left(J_{p}+g_{x}\right)} U_{\mathrm{a}}=0$

$\Theta_{\mathrm{a}}=\frac{E_{p} I_{p}\left(J_{p}+g_{x}\right)}{J_{p}\left(J_{p}-S_{p}\right)} \frac{\mathrm{d}^{3} U_{\mathrm{a}}}{\mathrm{d} z^{13}}+\frac{E_{p} I_{p} K_{p}+J_{p}^{2}}{J_{p}\left(J_{p}-S_{p}\right)} \frac{\mathrm{d} U_{\mathrm{a}}}{\mathrm{d} z^{\prime}}$

where $J_{p}, S_{p}$ and $K_{p}$ are defined as $J_{p}=\kappa G_{p} A_{p}, S_{p}=\rho_{p} I_{p} \omega^{2}, K_{p}=\rho_{p} A_{p} \omega^{2}-k_{x}-\mathrm{i} \omega c_{x}$ for brevity. It is noted from Eqs. (6-7) that 1) when $1 / J_{p} \rightarrow 0$ and $S_{p} \rightarrow 0$, it simplifies to the equation of an Euler pile on elastic soil; 2) when $g_{x}=0$, it reduces to the Winkler model. The general solution of Eq. (6) is

$U_{\mathrm{a}}\left(z^{\prime}\right)=A_{1} \cosh \alpha z^{\prime}+B_{1} \sinh \alpha z^{\prime}+C_{1} \cos \beta z^{\prime}+D_{1} \sin \beta z^{\prime}$

$150 \quad$ where $\alpha=\sqrt{\sqrt{\left[\frac{E_{p} I_{p} K_{p}-J_{p} g_{x}+S_{p}\left(J_{p}+g_{x}\right)}{2 E_{p} I_{p}\left(J_{p}+g_{x}\right)}\right]^{2}+\frac{K_{p}\left(J_{p}-S_{p}\right)}{E_{p} I_{p}\left(J_{p}+g_{x}\right)}}-\frac{E_{p} I_{p} K_{p}-J_{p} g_{x}+S_{p}\left(J_{p}+g_{x}\right)}{2 E_{p} I_{p}\left(J_{p}+g_{x}\right)}}$

and $\beta=\sqrt{\frac{E_{p} I_{p} K_{p}-J_{p} g_{x}+S_{p}\left(J_{p}+g_{x}\right)}{2 E_{p} I_{p}\left(J_{p}+g_{x}\right)}+\sqrt{\left[\frac{E_{p} I_{p} K_{p}-J_{p} g_{x}+S_{p}\left(J_{p}+g_{x}\right)}{2 E_{p} I_{p}\left(J_{p}+g_{x}\right)}\right]^{2}+\frac{K_{p}\left(J_{p}-S_{p}\right)}{E_{p} I_{p}\left(J_{p}+g_{x}\right)}}} \cdot A_{1}$,

$B_{1}, C_{1}, D_{1}$ are unknown initial coefficients, which can be determined based on the known boundary conditions. For a linear elastic Timoshenko pile, the bending moment $M_{\mathrm{a}}\left(\mathrm{z}^{\prime}\right)$ and shear force $Q_{\mathrm{a}}\left(\mathrm{z}^{\prime}\right)$ of the pile are related to the displacement $U_{\mathrm{a}}\left(\mathrm{z}^{\prime}\right)$ and rotation $\Theta_{\mathrm{a}}\left(\mathrm{z}^{\prime}\right)$ as follows:

$Q_{\mathrm{a}}\left(z^{\prime}\right)=J_{p}\left(\frac{\mathrm{d} U_{\mathrm{a}}\left(z^{\prime}\right)}{\mathrm{d} z^{\prime}}-\Theta_{\mathrm{a}}\left(z^{\prime}\right)\right)$

$M_{\mathrm{a}}\left(z^{\prime}\right)=E_{p} I_{p} \frac{\mathrm{d} \Theta_{\mathrm{a}}\left(z^{\prime}\right)}{\mathrm{d} z^{\prime}}$.

Using the initial parameter method (Wang et al. 2014b) with consideration of Eqs. (7-10), the relationship of both deflections and internal forces between the pile head and the pile tip can be expressed by a transfer matrix [TA]

$\left\{U_{\mathrm{a}}(L), \quad \Theta_{\mathrm{a}}(L), \quad Q_{\mathrm{a}}(L), \quad M_{\mathrm{a}}(L)\right\}^{T}=[\boldsymbol{T A}]\left\{U_{\mathrm{a}}(0), \quad \Theta_{\mathrm{a}}(0), \quad Q_{\mathrm{a}}(0), \quad M_{\mathrm{a}}(0)\right\}^{T}$

161 in which, $[\boldsymbol{T A}]=[\boldsymbol{t a}(L)][\boldsymbol{t a}(0)]^{-1}$. The algebraic expression for each element in $\left[\boldsymbol{t a}\left(z^{\prime}\right)\right]$ is given in 


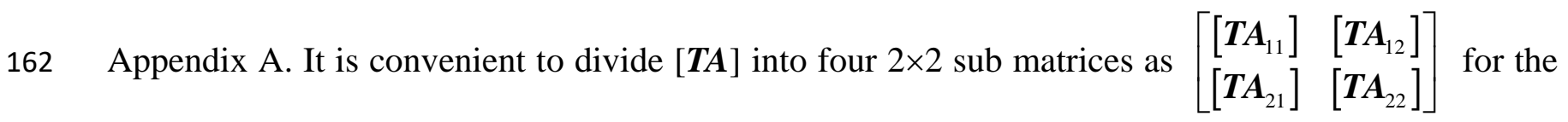
163 following formula derivation. Substituting the tip boundary condition $\left\{\begin{array}{l}Q_{\mathrm{a}}(L) \\ M_{\mathrm{a}}(L)\end{array}\right\}=\left[\boldsymbol{K}_{\text {tip }}^{x}\right]\left\{\begin{array}{l}U_{\mathrm{a}}(L) \\ \Theta_{\mathrm{a}}(L)\end{array}\right\}$ 164 into Eq. (11), the force-displacement relationship in the normal direction at the pile head can be 165 obtained

$166\left\{\begin{array}{c}Q_{\mathrm{a}}(0) \\ M_{\mathrm{a}}(0)\end{array}\right\}=\left[\Re_{x^{\prime}}\right]\left\{\begin{array}{c}U_{\mathrm{a}}(0) \\ \Theta_{\mathrm{a}}(0)\end{array}\right\}$

167 where the normal impedance matrix $\left[\mathfrak{R}_{x^{\prime}}\right]=\left(\left[\boldsymbol{K}_{\text {tip }}^{x}\right]\left[\boldsymbol{T} \boldsymbol{A}_{12}\right]-\left[\boldsymbol{T} \boldsymbol{A}_{22}\right]\right)^{-1}\left(\left[\boldsymbol{T} \boldsymbol{A}_{21}\right]-\left[\boldsymbol{K}_{\text {tip }}^{x}\right]\left[\boldsymbol{T} \boldsymbol{A}_{11}\right]\right)$.

168 During the axial steady-state harmonic vibration, the axial displacement of the pile can be 169 characterized by $w_{\mathrm{a}}=W_{\mathrm{a}} \mathrm{e}^{\mathrm{i} \omega t}$. As the axial vibration is not involved with the shear deformation, the 170 dynamic equilibrium yields the following governing equation

$171 \quad E_{p} A_{p} \frac{\mathrm{d}^{2} W_{\mathrm{a}}}{\mathrm{d} z^{\prime 2}}-\left(k_{z}+\mathrm{i} \omega c_{z}-\rho_{p} A_{p} \omega^{2}\right) W_{\mathrm{a}}=0$

172 The general solution of above equation is

$173 \quad W_{\mathrm{a}}\left(z^{\prime}\right)=A_{2} \cosh \left(\eta \mathrm{z}^{\prime}\right)+B_{2} \sinh \left(\eta \mathrm{z}^{\prime}\right)$

174 with $\eta=\sqrt{\frac{k_{z}+\mathrm{i} \omega c_{z}-\rho_{p} A_{p} \omega^{2}}{E_{p} A_{p}}}$.

175 The axial force in the pile can be obtained from the differential relationship $176 \quad N_{\mathrm{a}}\left(z^{\prime}\right)=E_{p} A_{p} \frac{\mathrm{d} W_{\mathrm{a}}}{\mathrm{d} z^{\prime}}$. The mechanical property between the pile head and tip can be expressed by the 177 transfer matrix $[\boldsymbol{T B}]$ as follows

$178\left\{\begin{array}{l}W_{\mathrm{a}}(L) \\ N_{\mathrm{a}}(L)\end{array}\right\}=[\boldsymbol{T} \boldsymbol{B}]\left\{\begin{array}{l}W_{\mathrm{a}}(0) \\ N_{\mathrm{a}}(0)\end{array}\right\}$

179 in which, $[\boldsymbol{T B}]=[\boldsymbol{t} \boldsymbol{b}(L)][\boldsymbol{t} \boldsymbol{b}(0)]^{-1}$. The algebraic expression for $\left[\boldsymbol{t} \boldsymbol{b}\left(z^{\prime}\right)\right]$ is given in Appendix B. 180 Substituting the tip boundary condition $N_{\mathrm{a}}(L)=K_{\text {tip }}^{z} W_{\mathrm{a}}(L)$ into Eq. (15), the force-displacement 181 relationship in the axial direction at the pile head can be obtained

$182 \quad N_{\mathrm{a}}(0)=\mathfrak{R}_{z} W_{\mathrm{a}}(0)$ 
183 where the axial impedance $\mathfrak{R}_{z^{\prime}}=\frac{T B_{2,1}-K_{\text {tip }}^{z} T B_{1,1}}{K_{\text {tip }}^{z} T B_{1,2}-T B_{2,2}}$. Here, $T B_{i, j}$ represents the element in the $i$-th row and $j$-th column of matrix [TB].

Considering the transformation of the coordinate system between the local and global axes of the inclined pile, the horizontal impedance of the inclined pile $\mathfrak{R}_{\mathrm{h}}$ at the pile head is given by :

$\mathfrak{R}_{\mathrm{h}}=\frac{\mathfrak{R}_{z^{\prime}} \mathfrak{R}_{x^{\prime} 1,1}}{\mathfrak{R}_{z^{\prime}} \cos ^{2}\left(\varphi_{1}\right)+\mathfrak{R}_{x^{\prime} 1,1} \sin ^{2}\left(\varphi_{1}\right)}$

where $\mathfrak{R}_{x^{\prime} 1,1}$ is the element in the first row and first column of the matrix $\left[\mathfrak{R}_{x}{ }^{\prime}\right] . \mathfrak{R}_{\mathrm{h}}$ is a complex value. The real part $K_{\mathrm{h}}$ represents the dynamic stiffness, while the imaginary part $C_{\mathrm{h}}$ represents the damping ratio.

\section{Dynamic interaction of adjacent inclined piles}

In addition to the loads transmitted from the pile cap, each inclined pile in a group experiences the action from both the normal and axial vibrations of surrounding piles. To better understand the dynamic interaction between adjacent inclined piles, a pair of inclined piles with inclined angles $\varphi_{1}$ and $\varphi_{2}$ to the vertical global axis respectively is considered as shown in Fig. 2. The T-P model is developed for evaluating the normal cross interaction between two piles. The normal-normal interaction factor $\lambda_{\mathrm{nn}}$ and the axial-normal interaction factor $\lambda_{\mathrm{an}}$ are defined as the ratios of the normal displacement at the head of the receiver pile, which is caused by the horizontal vibration of the source pile, to the normal and axil displacements at the head of the source pile respectively. The axial cross dynamic interaction, in which the shear effect of both soil and piles can be neglected (Ghasemzadeh and Alibeikloo 2011), is not studied in this paper as it has been properly solved by the classical E-W model. The derivations of $\lambda_{\mathrm{nn}}$ and $\lambda_{\mathrm{an}}$ are given in following sections.

The kinetic source pile could excite the surrounding soil and transfer the waves to receiver piles. Based on the coordinate transformation, the normal displacement of the soil around the receiver pile, induced by the normal vibration of the source pile can be obtained by the attenuation factor $f_{x}(s, \phi)$ :

$U_{s}^{(1)}=U_{\mathrm{a}} f_{x}(s, \phi) \cos \left(\varphi_{1}+\varphi_{2}\right)$

where $\phi$ is the angle between the center-line direction of two piles and the direction of the applied horizontal force, as shown in Fig. 2b. $s$ is the center distance between two piles.

According to the model developed by Dobry and Gazetas (1988), the attenuation factor 
211 follows:

213 in which, $f_{x}(s, 0)=\sqrt{\frac{d}{2 s}} \exp \left[\frac{-\omega\left(\beta_{\mathrm{s}}+\mathrm{i}\right)(s-d / 2)}{V_{\mathrm{La}}}\right]$ and $f_{x}\left(s, \frac{\pi}{2}\right)=\sqrt{\frac{d}{2 s}} \exp \left[\frac{-\omega\left(\beta_{\mathrm{s}}+\mathrm{i}\right)(s-d / 2)}{V_{\mathrm{s}}}\right]$.

The vertical displacement field around the receiver pile also can be approximately evaluated by the factor $f_{z}(s)$ as follows (Dobry and Gazetas 1988)

$$
f_{z}(s)=\sqrt{\frac{d}{2 s}} \exp \left[\frac{-\omega s\left(\beta_{\mathrm{s}}+\mathrm{i}\right)}{V_{\mathrm{s}}}\right]
$$

Similarly, the normal displacement of the soil around the receiver pile induced by the axial vibration of the source pile can be obtained:

$$
U_{s}^{(2)}=W_{\mathrm{a}} f_{z}(s) \sin \left(\varphi_{1}+\varphi_{2}\right)
$$

\section{Normal-normal interaction factor}

Considering the dynamic interaction between the soil and the receiver pile, the normal dynamic equilibrium equation of the receiver pile, which is induced by the normal vibration of the source pile, is expressed as

$$
\frac{d^{4} U_{\mathrm{b}}^{(1)}}{d z^{14}}+\frac{E_{p} I_{p} K_{p}-J_{p} g_{x}+S_{p}\left(J_{p}+g_{x}\right)}{E_{p} I_{p}\left(J_{p}+g_{x}\right)} \frac{d^{2} U_{\mathrm{b}}^{(1)}}{d z^{12}}-\frac{K_{p}\left(J_{p}-S_{p}\right)}{E_{p} I_{p}\left(J_{p}+g_{x}\right)} U_{\mathrm{b}}^{(1)}=f_{x 1} U_{s}^{(1)}+f_{x 2} \frac{\mathrm{d}^{2} U_{s}^{(1)}}{\mathrm{d} z^{12}}+f_{x 3} \frac{\mathrm{d}^{4} U_{s}^{(1)}}{\mathrm{d} z^{1^{4}}}
$$

225 in which, $f_{x 1}=\frac{\left(J_{p}-S_{p}\right)\left(k_{x}+\mathrm{i} \omega c_{x}\right)}{E_{p} I_{p}\left(J_{p}+g_{x}\right)} ; f_{x 2}=\frac{E_{p} I_{p}\left(k_{x}+\mathrm{i} \omega c_{x}\right)-S_{p} g_{x}}{E_{p} I_{p}\left(J_{p}+g_{x}\right)} ; f_{x 3}=\frac{g_{x}}{J_{p}+g_{p}} . \quad U_{\mathrm{b}}^{(1)}$ is the normal displacement of the receiver pile induced by the normal vibration of the source pile.

227 The complete solution for Eq. (22) is

$U_{\mathrm{b}}^{(1)}\left(z^{\prime}\right)=A_{3} \cosh \alpha z^{\prime}+B_{3} \sinh \alpha z^{\prime}+C_{3} \cos \beta z^{\prime}+D_{3} \sin \beta z^{\prime}+$

$$
z F_{a}\left(A_{1} \sinh \alpha z^{\prime}+B_{1} \cosh \alpha z^{\prime}\right)+z F_{b}\left(-C_{1} \sin \beta z^{\prime}+D_{1} \cos \beta z^{\prime}\right)
$$

where $F_{a}=\frac{f_{x 1}+f_{x 2} \alpha^{2}+f_{x 3} \alpha^{4}}{2 \alpha\left(2 \alpha^{2}+\delta^{2}\right)} f_{x}(s, \phi) \cos \left(\varphi_{1}+\varphi_{2}\right), \quad F_{b}=\frac{f_{x 1}-f_{x 2} \beta^{2}+f_{x 3} \beta^{4}}{2 \beta\left(2 \beta^{2}-\delta^{2}\right)} f_{x}(s, \phi) \cos \left(\varphi_{1}+\varphi_{2}\right)$. written in a matrix form: 


$$
\left\{\begin{array}{c}
U_{\mathrm{b}}^{(1)}(L) \\
\Theta_{\mathrm{b}}^{(1)}(L) \\
Q_{\mathrm{b}}^{(1)}(L) \\
M_{\mathrm{b}}^{(1)}(L)
\end{array}\right\}=[\boldsymbol{T A}]\left\{\begin{array}{c}
U_{\mathrm{b}}^{(1)}(0) \\
\Theta_{\mathrm{b}}^{(1)}(0) \\
Q_{\mathrm{b}}^{(1)}(0) \\
M_{\mathrm{b}}^{(1)}(0)
\end{array}\right\}+[\boldsymbol{T C}]\left\{\begin{array}{c}
U_{\mathrm{a}}(0) \\
\Theta_{\mathrm{a}}(0) \\
Q_{\mathrm{a}}(0) \\
M_{\mathrm{a}}(0)
\end{array}\right\}
$$

where $[\boldsymbol{T C}]=-[\boldsymbol{t a}(L)][\boldsymbol{t a}(0)]^{-1}[\boldsymbol{t c}(0)][\boldsymbol{t a}(0)]^{-1}+[\boldsymbol{t c}(L)][\boldsymbol{t a}(0)]^{-1}$. The algebraic expression for

$234\left[\operatorname{tc}\left(z^{\prime}\right)\right]$ is given in Appendix C. By substituting the boundary conditions at the tip of the receiver

235 pile $\left\{\begin{array}{c}Q_{\mathrm{b}}^{(1)}(L) \\ M_{\mathrm{b}}^{(1)}(L)\end{array}\right\}=\left[\boldsymbol{K}_{\text {tip }}^{x}\right]\left\{\begin{array}{l}U_{\mathrm{b}}^{(1)}(L) \\ \Theta_{\mathrm{b}}^{(1)}(L)\end{array}\right\}$ into Eq. (23), we have

$[\boldsymbol{T} 1]\left\{\begin{array}{c}U_{\mathrm{b}}^{(1)}(0) \\ \Theta_{\mathrm{b}}^{(1)}(0)\end{array}\right\}+[\boldsymbol{T} 2]\left\{\begin{array}{c}Q_{\mathrm{b}}^{(1)}(0) \\ M_{\mathrm{b}}^{(1)}(0)\end{array}\right\}+[\boldsymbol{T} 3]\left\{\begin{array}{c}U_{\mathrm{b}}^{(1)}(0) \\ \Theta_{\mathrm{b}}^{(1)}(0)\end{array}\right\}=\left\{\begin{array}{l}0 \\ 0\end{array}\right\}$

in which, $[\boldsymbol{T 1}]=\left[\boldsymbol{K}_{\text {tip }}^{x}\right]\left[\boldsymbol{T A _ { 1 1 }}\right]-\left[\boldsymbol{T \boldsymbol { A } _ { 2 1 }}\right] ; \quad[\boldsymbol{T} \mathbf{2}]=\left[\boldsymbol{K}_{\text {tip }}^{x}\right]\left[\boldsymbol{T \boldsymbol { A } _ { 1 2 }}\right]-\left[\boldsymbol{T} \boldsymbol{A}_{22}\right]$;

$[\boldsymbol{T 3}]=\left[\boldsymbol{K}_{\text {tip }}^{x}\right]\left[\boldsymbol{T} \boldsymbol{C}_{11}\right]-\left[\boldsymbol{T} \boldsymbol{C}_{21}\right]+\left(\left[\boldsymbol{K}_{\text {tip }}^{x}\right]\left[\boldsymbol{T} \boldsymbol{C}_{12}\right]-\left[\boldsymbol{T} \boldsymbol{C}_{22}\right]\right)\left[\mathfrak{R}_{x^{\prime}}\right]$

For the case of a fixed pile-to-cap connection, the boundary conditions at the head of the

receiver pile are satisfied as $Q_{\mathrm{b}}^{(1)}(0)=0$ and $\Theta_{\mathrm{b}}^{(1)}(0)=0$. Submitting Eq. (12) and above boundary

conditions into Eq. (25), the normal-normal interaction factor $\lambda_{\mathrm{nn}}$ is given by

$$
\lambda_{\mathrm{nn}}=\frac{U_{\mathrm{b}}^{(1)}(0)}{U_{\mathrm{a}}(0)}=\frac{T 3_{2,1} T 2_{1,2}-T 3_{1,1} T 2_{2,2}}{T 1_{1,1} T 2_{2,2}-T 1_{2,1} T 2_{1,2}}
$$

\section{Axial-normal interaction factor}

Considering the dynamic interaction between the soil and the receiver pile, the normal dynamic

equilibrium equation of the receiver pile, which is induced by the axial vibration of the source pile, is

expressed as:

$\frac{d^{4} U_{\mathrm{b}}^{(2)}}{d z^{14}}+\frac{E_{p} I_{p} K_{p}-J_{p} g_{x}+S_{p}\left(J_{p}+g_{x}\right)}{E_{p} I_{p}\left(J_{p}+g_{x}\right)} \frac{d^{2} U_{\mathrm{b}}^{(2)}}{d z^{12}}-\frac{K_{p}\left(J_{p}-S_{p}\right)}{E_{p} I_{p}\left(J_{p}+g_{x}\right)} U_{\mathrm{b}}^{(2)}=f_{z 1} U_{s}^{(2)}+f_{z 2} \frac{\mathrm{d}^{2} U_{s}^{(2)}}{\mathrm{d} z^{\prime 2}}+f_{z 3} \frac{\mathrm{d}^{4} U_{s}^{(2)}}{\mathrm{d} z^{14}}$

248

where $f_{z 1}=\frac{\left(J_{p}-S_{p}\right)\left(k_{x}+\mathrm{i} \omega c_{x}\right)}{E_{p} I_{p}\left(J_{p}+g_{x}\right)} ; \quad f_{z 2}=\frac{E_{p} I_{p}\left(k_{x}+\mathrm{i} \omega c_{x}\right)-S_{p} g_{x}}{E_{p} I_{p}\left(J_{p}+g_{x}\right)} ; f_{z 3}=\frac{g_{x}}{J_{p}+g_{x}} . U_{\mathrm{b}}^{(2)} \quad$ is the

normal displacement of the receiver pile induced by the axial vibration of the source pile. 
The solution of equation (27) is:

252 in which, $F_{c}=\frac{f_{z 1}+f_{z 2} \eta^{2}+f_{z 3} \eta^{4}}{\eta^{4}+\delta^{2} \eta^{2}-\lambda^{4}} f_{z}(s) \sin \left(\varphi_{1}+\varphi_{2}\right)$.

253 The relationship of deflections and internal forces at the tip of the receiver pile can be written in 254 the following matrix form

$$
\left\{\begin{array}{c}
U_{\mathrm{b}}^{(2)}(L) \\
\Theta_{\mathrm{b}}^{(2)}(L) \\
Q_{\mathrm{b}}^{(2)}(L) \\
M_{\mathrm{b}}^{(2)}(L)
\end{array}\right\}=[\boldsymbol{T A}]\left\{\begin{array}{c}
U_{\mathrm{b}}^{(2)}(0) \\
\Theta_{\mathrm{b}}^{(2)}(0) \\
Q_{\mathrm{b}}^{(2)}(0) \\
M_{\mathrm{b}}^{(2)}(0)
\end{array}\right\}+[\boldsymbol{T D}]\left\{\begin{array}{c}
W_{\mathrm{a}}(0) \\
N_{\mathrm{a}}(0)
\end{array}\right\}
$$

256 where $[\boldsymbol{T D}]=[\boldsymbol{t d}(L)][\boldsymbol{t} \boldsymbol{b}(0)]^{-1}-[\boldsymbol{t a}(L)][\boldsymbol{t a}(0)]^{-1}[\boldsymbol{t d}(0)][\boldsymbol{t} \boldsymbol{b}(0)]^{-1}$. The algebraic expression for $257\left[\boldsymbol{t d}\left(z^{\prime}\right)\right]$ is given in Appendix D. By applying the boundary conditions at the receiver pile tip $258\left\{\begin{array}{c}Q_{\mathrm{b}}^{(2)}(L) \\ M_{\mathrm{b}}^{(2)}(L)\end{array}\right\}=\left[\boldsymbol{K}_{\text {tip }}^{x}\right]\left\{\begin{array}{l}U_{\mathrm{b}}^{(2)}(L) \\ \Theta_{\mathrm{b}}^{(2)}(L)\end{array}\right\}$ to Eq. (29), We have

$$
[\boldsymbol{T 1}]\left\{\begin{array}{c}
U_{\mathrm{b}}^{(2)}(0) \\
\Theta_{\mathrm{b}}^{(2)}(0)
\end{array}\right\}+[\boldsymbol{T 2}]\left\{\begin{array}{c}
Q_{\mathrm{b}}^{(2)}(0) \\
M_{\mathrm{b}}^{(2)}(0)
\end{array}\right\}+[\boldsymbol{T} 4]\left\{\begin{array}{c}
W_{\mathrm{a}}(0) \\
N_{\mathrm{a}}(0)
\end{array}\right\}=\left\{\begin{array}{l}
0 \\
0
\end{array}\right\}
$$

260 in which, $[\boldsymbol{T 4}]=\left[\boldsymbol{K}_{\text {tip }}^{x}\right]\left[\begin{array}{ll}T D_{1,1} & T D_{1,2} \\ T D_{2,1} & T D_{2,2}\end{array}\right]-\left[\begin{array}{ll}T D_{3,1} & T D_{3,2} \\ T D_{4,1} & T D_{4,2}\end{array}\right]$. and $\Theta_{\mathrm{b}}^{(2)}(0)=0$ ), into Eq. (30), the axial-normal interaction factor $\lambda_{\mathrm{an}}$ can be obtained as:

$$
\lambda_{\mathrm{an}}=\frac{U_{\mathrm{b}}^{(2)}(0)}{W_{\mathrm{a}}(0)}=\frac{\left(T 4_{2,1}+T 4_{2,2} \Re_{z^{\prime}}\right) T 2_{1,2}-\left(T 4_{1,1}+T 4_{1,2} \Re_{z^{\prime}}\right) T 2_{2,2}}{T 1_{1,1} T 2_{2,2}-T 1_{2,1} T 2_{1,2}}
$$

\section{Comparison with Numerical models \\ Verification of T-P model for a single inclined pile}

To verify the effectiveness of the present T-P model, the static stiffness and the horizontal 
Figs. 3 and 4. The results given by Giannakou et al. (2006) are obtained by developing a simplified equation based on the 3-D FEM model. The results given by Padron et al. (2010) are obtained by using the FEM-BEM model. It can be seen from Figs. 3 and 4 that the analytical results obtained by

271 the present T-P model are in agreement with those obtained by BEM-FEM model. The maximum 272 difference is less than $15 \%$. In addition, with the increasing of the inclined angle the static stiffness 273 obtained from the estimating equations (Giannakou et al., 2006) gradually deviates from those 
between the present solutions and the rigorous FE-BE solutions from Saitoh et al (2016) because the present model utilizes an attenuation function with approximately-assumed wave propagation given by Dobry and Gazetas (1988) to simulate the pile-to-pile interaction effect. If one wants to obtain a better accuracy of the interaction factors, the present attenuation function used for inclined piles should be further improved.

\section{Numerical examples and discussions}

\section{Shear effect of the inclined pile on the horizontal impedance}

Based on an improved plane-strain foundation model and the Euler beam theory, Mylonakis (2001) studied the stiffness at the head of a vertical large-diameter end-bearing pile for different pile-soil modulus ratios $E_{\mathrm{p}} / E_{\mathrm{s}}$ and different slenderness ratios $L / d$. A comparison of the results between the present model and Mylonakis' model is shown in Table 1. The Young's modulus in [ $\left.\boldsymbol{K}_{\text {tip }}\right]$ is given a large enough value $E_{\mathrm{tip}}=10 E_{\mathrm{p}}$ in the calculation to simulate the rigid base considered by Mylonakis (2001). As show in Table 1, the maximum relative error between the results from the two models is up to $30 \%$ for $L / d=5$ while it drops below $3.0 \%$ for $L / d=10$, due to the salient shear effect for the piles with small slenderness ratios. This example is also used to check the influence of the inclined angle on the horizontal stiffness. It can be seen from Table 1 that the horizontal stiffness at the pile head increases with the increase of the inclined angle. It is confirmed that the use of inclined piles is advantageous in supporting horizontal loadings.

Moreover, T-P model can be reduced to an Euler beam-on-Pasternak-foundation model (E-P) model when $1 / J_{p} \rightarrow 0$ and $S_{p} \rightarrow 0$. Fig. 10 shows the stiffness variation with respect to slenderness ratio of the T-P model and the E-P model for $E_{\mathrm{p}} / E_{\mathrm{s}}=100,300$ and 1000 , respectively. It can be seen from Fig. 10 that the results from the E-P model approach to those from the T-P model as the 
slenderness ratio $L / d$ increases. It can be seen from Fig. 10 that the results from T-P model are smaller than those from E-P model, especially for low slenderness ratios because the E-P model ignores the effects of shear deformation and rotational inertia of piles.

\section{Shear effect of the soil on horizontal impedance}

Fig. 11 and Fig. 12 show the comparison of horizontal impedances obtained from the T-P model and the E-W model for different pile-soil elastic modulus ratios $E_{\mathrm{p}} / E_{\mathrm{s}}$ and different inclined angles $\varphi$. It can be seen from Fig.11 that the results from T-P model are larger than those from the E-W model, especially for small pile-soil elastic modulus ratios. As a large slenderness ratio $L / d=15$ is considered in the calculation, this relative difference between the T-P model and the E-W model in Fig. 11 is mainly caused by the shear effect of soil. It can be seen from Fig. 12 that the dynamic stiffness of an inclined pile obtained from T-P model is also higher than that from the E-W model while the two models provide similar damping. In addition, it is indicated from Fig. 12 that the shear deformation of soil has a greater impact on piles with larger inclined angles by comparing the relative differences between two models for the three inclined angles $\left(\varphi=10^{\circ}, 20^{\circ}, 30^{\circ}\right)$.

\section{Influence of the shear effects on interaction factors}

Now, we study a soil medium with average shear wave velocity $V_{\mathrm{s}}=200 \mathrm{~m} / \mathrm{s}$ and the piles with diameter $d=1 \mathrm{~m}$. A typical seismic excitation with dominant period $T=0.15 \mathrm{~s}$ is considered in the following analysis. In such a case, $a_{0}=0.2$. Fig.13 and Fig. 14 show the variations of normal-normal and axial-normal interaction factors with the slenderness ratio for different models. It can be seen from Fig. 13 that the normal-normal interaction factor obtained from the Timoshenko pile model is lower than those obtained from the Euler pile model for a small slenderness ratio. However, the difference decreases with the increase of the slenderness ratio. Fig. 14 indicates that the shear effect 
334 of the inclined pile has almost no influence on axial-normal interaction factors. This is because that 335 the vibration of the source pile does not induce the shear deformation in the axial direction. 336 Moreover, with the increase of the slenderness ratio, the interaction factors approach to constant 337 values which are close to the results obtained by Ghasemzadeh and Alibeikloo (2011), as seen from $338 \quad$ Fig. 13 and Fig. 14.

339 Influence of the inclined angle on interaction factors

The normal-normal interaction factor $\lambda_{\mathrm{nn}}$ and axial-normal interaction factor $\lambda_{\mathrm{an}}$, as functions of 341 inclined angles for a small slenderness ratios $L / d=5$ and a large slenderness ratio $L / d=25$, are 342 presented in Fig. 15 and Fig. 16, respectively. It is assumed that inclined angles for the source pile 343 and receiver pile are the same $\left(\varphi_{1}=\varphi_{2}\right)$. It can be seen from Fig. 15 that $\lambda_{\text {nn }}$ decreases with the 344 increase of the inclined angle. In contrast, $\lambda_{\mathrm{an}}$ increases with the increase of inclined angle as shown 345 in Fig. 16. Moreover, comparing the slopes of two curves in Fig. 15 (or in Fig. 16) shows that the 346 interaction factor of inclined pile with smaller slenderness ratio is more susceptible to the inclined 347 angle. As a result, choosing an optimum inclined angle in the pile group needs further considerations 348 when the slenderness ratio of inclined piles is small.

\section{Conclusion}

embedded in homogeneous elastic half-space are developed based on the T-P model. The normal reaction of the soil against the pile shaft is simulated by the Pasternak's foundation modulus with springs, dashpots and the shear layer. The reaction of the soil against the pile tip is simulated by three springs in parallel with dashpots. The vibration of the inclined pile is analyzed by the Timoshenko 
356 of shear deformations on both soil and inclined piles are highlighted by comparing the results from 357 the T-P model and the E-W model. The influence of the inclined angle on the horizontal impedance 358 and interaction factors are presented by numerical parametric studies. The following main aspects 359 can be emphasized:

360 - The relative difference of the horizontal dynamic stiffness between the T-P model and E-W 361 model increases with the increase of the inclined angle and the decrease of the slenderness ration $362(L / d)$. Therefore, it is important to take the shear effect of both soil and piles into account for 363 those piles with large inclined angle and small slenderness ratio.

364 - The inclined angle has a significant influence on both horizontal impedance for a single pile and 365 interaction factors for adjacent piles. It is demonstrated that increasing the inclined angle results 366 in increases of horizontal impedance and axial-normal interaction factor, while results in a 367 decrease of normal-normal interaction factor. Therefore an optimum inclined angle for the 368 inclined piles in a group needs to be studied. 


\section{Appendix A}

370 The algebraic expression for $\left[\operatorname{ta}\left(z^{\prime}\right)\right]$ is given as follows:

$371 \quad\left[\operatorname{ta}\left(z^{\prime}\right)\right]=\left\{a_{1}, a_{2}, a_{3}, a_{4}\right\}^{T}$

372 in which,

$373\left\{\boldsymbol{a}_{1}\right\}=\left\{\cosh \left(\alpha z^{\prime}\right) \quad \sinh \left(\alpha z^{\prime}\right) \quad \cos \left(\beta z^{\prime}\right) \quad \sin \left(\beta z^{\prime}\right)\right\}$

$374 \quad\left\{\boldsymbol{a}_{2}\right\}=\left\{\begin{array}{c}\left(\Phi \alpha+\Upsilon \alpha^{3}\right) \sinh \left(\alpha z^{\prime}\right) \\ \left(\Phi \alpha+\Upsilon \alpha^{3}\right) \cosh \left(\alpha z^{\prime}\right) \\ \left(-\Phi \beta+\Upsilon \beta^{3}\right) \sin \left(\beta z^{\prime}\right) \\ \left(\Phi \beta-\Upsilon \beta^{3}\right) \cos \left(\beta z^{\prime}\right)\end{array}\right\}$

$375 \quad\left\{\boldsymbol{a}_{3}\right\}=\left\{\begin{array}{l}\left(\Psi \alpha+J_{p} \Upsilon \alpha^{3}\right) \sinh \left(\alpha z^{\prime}\right) \\ \left(\Psi \alpha+J_{p} \Upsilon \alpha^{3}\right) \cosh \left(\alpha z^{\prime}\right) \\ \left(-\Psi \beta+J_{p} \Upsilon \beta^{3}\right) \sin \left(\beta z^{\prime}\right) \\ \left(\Psi \beta-J_{p} \Upsilon \beta^{3}\right) \cos \left(\beta z^{\prime}\right)\end{array}\right\}^{T}$

$376 \quad\left\{\boldsymbol{a}_{4}\right\}=\left\{\begin{array}{c}-\left(\Phi \alpha^{2}+\Upsilon \alpha^{4}\right) E_{p} I_{p} \cosh \left(\alpha z^{\prime}\right) \\ -\left(\Phi \alpha^{2}+\Upsilon \alpha^{4}\right) E_{p} I_{p} \sinh \left(\alpha z^{\prime}\right) \\ \left(\Phi \beta^{2}-\Upsilon \beta^{4}\right) E_{p} I_{p} \cos \left(\beta z^{\prime}\right) \\ \left(\Phi \beta^{2}-\Upsilon \beta^{4}\right) E_{p} I_{p} \sin \left(\beta z^{\prime}\right)\end{array}\right\}^{T}$

377 with $\Phi=\frac{J_{p}{ }^{2}+K_{p} E_{p} I_{p}}{J_{p}\left(J_{p}-S_{p}\right)}, \Psi=\frac{K_{p} E_{p} I_{p}+J_{p} S_{p}}{J_{p}-W_{p}}, \Upsilon=\frac{E_{p} I_{p}\left(J_{p}+g_{x}\right)}{J_{p}\left(J_{p}-S_{p}\right)}$.

378

379 Appendix B

380 The algebraic expression for $\left[t \boldsymbol{b}\left(z^{\prime}\right)\right]$ is given as follows:

$381 \quad\left[\boldsymbol{t} \boldsymbol{b}\left(z^{\prime}\right)\right]=\left[\begin{array}{cc}\cosh \left(\eta z^{\prime}\right) & \sinh \left(\eta z^{\prime}\right) \\ \eta E_{p} A_{p} \sinh \left(\eta z^{\prime}\right) & \eta E_{p} A_{p} \cosh \left(\eta z^{\prime}\right)\end{array}\right]$

382

\section{Appendix C}

384 The algebraic expression for $\left[t c\left(z^{\prime}\right)\right]$ is given as follows: 
386 in which,

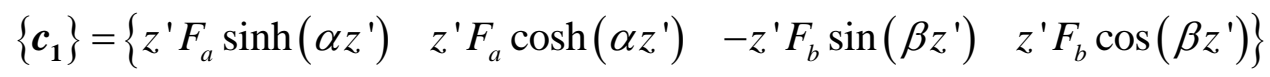

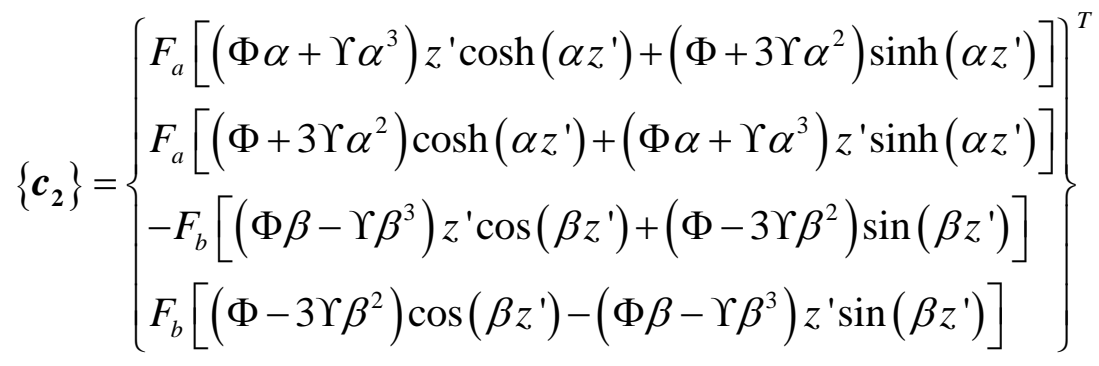

390

$$
\left\{\boldsymbol{c}_{3}\right\}=\left\{\begin{array}{l}
F_{a}\left\{\alpha\left(\Psi+J_{p} \Upsilon \alpha^{2}\right) z^{\prime} \cosh \left(\alpha z^{\prime}\right)+\left(\Psi+3 J_{p} \Upsilon \alpha^{2}\right) \sinh \left(\alpha z^{\prime}\right)\right\} \\
F_{a}\left\{\left(\Psi+3 J_{p} \Upsilon \alpha^{2}\right) \cosh \left(\alpha z^{\prime}\right)+\alpha\left(\Psi+J_{p} \Upsilon \alpha^{2}\right) z^{\prime} \sinh \left(\alpha z^{\prime}\right)\right\} \\
-F_{b}\left\{\beta\left(\Psi-J_{p} \Upsilon \beta^{2}\right) z^{\prime} \cos \left(\beta z^{\prime}\right)+\left(\Psi-3 J_{p} \Upsilon \beta^{2}\right) \sin \left(\beta z^{\prime}\right)\right\} \\
F_{b}\left\{\left(\Psi-3 J_{p} \Upsilon \beta^{2}\right) \cos \left(\beta z^{\prime}\right)-\beta\left(\Psi-J_{p} \Upsilon \beta^{2}\right) z^{\prime} \sin \left(\beta z^{\prime}\right)\right\}
\end{array}\right\}
$$$$
\left\{\boldsymbol{c}_{4}\right\}=\left\{\begin{array}{l}
-F_{a} E_{p} I_{p}\left[2 \alpha\left(\Phi+2 \alpha^{2} \Upsilon\right) \cosh \left(\alpha z^{\prime}\right)+\alpha^{2}\left(\Phi+\alpha^{2} \Upsilon\right) z^{\prime} \sinh \left(\alpha z^{\prime}\right)\right] \\
-F_{a} E_{p} I_{p}\left[\alpha^{2}\left(\Phi+\alpha^{2} \Upsilon\right) z^{\prime} \cosh \left(\alpha z^{\prime}\right)+2 \alpha\left(\Phi+2 \alpha^{2} \Upsilon\right) \sinh \left(\alpha z^{\prime}\right)\right] \\
F_{b} E_{p} I_{p}\left[2 \beta\left(\Phi-2 \beta^{2} \Upsilon\right) \cos \left(\beta z^{\prime}\right)-\beta^{2}\left(\Phi-\beta^{2} \Upsilon\right) z^{\prime} \sin \left(\beta z^{\prime}\right)\right] \\
F_{b} E_{p} I_{p}\left[\beta^{2}\left(\Phi-\beta^{2} \Upsilon\right) z^{\prime} \cos \left(\beta z^{\prime}\right)+2 \beta\left(\Phi-2 \beta^{2} \Upsilon\right) \sin \left(\beta z^{\prime}\right)\right]
\end{array}\right\}
$$

\section{Appendix D}

393 The algebraic expression for $\left[t d\left(z^{\prime}\right)\right]$ is given as follows:

$$
394 \quad\left[\operatorname{td}\left(z^{\prime}\right)\right]=\left[\begin{array}{cc}
F_{c} \cosh \left(\eta z^{\prime}\right) & F_{c} \sinh \left(\eta z^{\prime}\right) \\
F_{c}\left(\Phi \eta+\Upsilon \eta^{3}\right) \sinh \left(\eta z^{\prime}\right) & F_{c}\left(\Phi \eta+\Upsilon \eta^{3}\right) \cosh \left(\eta z^{\prime}\right) \\
F_{c}\left(\Psi \eta+J_{p} \Upsilon \eta^{3}\right) \sinh \left(\eta z^{\prime}\right) & F_{c}\left(\Psi \eta+J_{p} \Upsilon \eta^{3}\right) \cosh \left(\eta z^{\prime}\right) \\
-F_{c}\left(\Phi \eta^{2}+\Upsilon \eta^{4}\right) E_{p} I_{p} \cosh \left(\eta z^{\prime}\right) & -F_{c}\left(\Phi \eta^{2}+\Upsilon \eta^{4}\right) E_{p} I_{p} \sinh \left(\eta z^{\prime}\right)
\end{array}\right]
$$




\section{Acknowledgments}

398 The financial supports from the National Natural Science Foundation of China (51678302) and 399 Fundamental Research Funds for the Central Universities (2016B15014) are greatly acknowledged.

400 This work is also supported in part by the scholarship from China Scholarship Council (CSC) under 401 the Grant No. 201408320149. 


\section{$402 \quad$ Notation list}

403 The following symbols are used in this paper:

$404 A_{p}=$ cross-section area of the pile;

$405 a_{0}=$ dimensionless frequency of the excitation;

$406 C_{\mathrm{h}}=$ horizontal damping ratio at the pile head;

$407 \quad c_{x}, c_{z}=$ normal and axial damping along the pile shaft;

$408 d=$ sectional diameter of the inclined pile;

$409 E_{p}, E_{s}=$ Young's modulus of the pile and the soil along the pile shaft, respectively;

$410 G_{s}, G_{s}$,tip $=$ Shear modulus of the soil along the pile shaft and under the pile tip, respectively;

$411 g_{x}=$ shear stiffness of the soil along the pile shaft;

$412 \quad I_{p}=$ inertia moment of the pile;

$413 \quad K_{\mathrm{h}}=$ horizontal dynamic stiffness at the pile head;

$414 K_{\text {tip }}^{z}=$ axial base impedance of the pile;

$415\left[\boldsymbol{K}_{\text {tip }}^{x}\right]=$ normal base impedance of the pile;

$416 k_{x}, k_{z}=$ normal and axial stiffness along the pile shaft;

$417 \quad L=$ length of the inclined pile-shaft;

$418 M_{\mathrm{a}}, M_{\mathrm{b}}^{(j)}=$ bending moment of a source pile; rotation of a receiver pile induced by the vibration of the source pile in the $j$ direction;

$420 \quad N_{\mathrm{a}}=$ axial force of a source pile;

$421 Q_{\mathrm{a}}, Q_{\mathrm{b}}^{(j)}=$ shear force of a source pile; rotation of a receiver pile induced by the vibration of the source pile in the $j$ direction; $s=$ center to center distance between two piles;

$U_{\mathrm{a}}, U_{\mathrm{b}}^{(j)}=$ normal displacement of a source pile; normal displacement of a receiver pile induced by the vibration of the source pile in $j$ direction. $j=1$ for normal direction, $j=2$ for axial

$427 \quad V_{s}=$ shear wave velocity of the soil;

$W_{\mathrm{a}}=$ axial displacement of a source pile;

$\phi=$ angle between the center-line direction of two piles; 
$430 \omega=$ frequency of the harmonic excitation;

$431 \varphi_{1}, \varphi_{2}=$ inclined angle of the source pile and the receiver pile, respectively;

$432 \lambda_{\mathrm{nn}}, \lambda_{\mathrm{an}}=$ dynamic interaction factors in the normal-normal and axial-normal directions;

$433 v_{p}, v_{s}=$ Poisson's ratio of the pile and the soil, respectively;

$434 \rho_{p}, \rho_{s}=$ mass density of the pile and the soil, respectively;

$435 \quad \beta_{s}=$ radiation damping of the soil;

$436 \mathfrak{R}_{\mathrm{z}^{\prime}}=$ axial impedance matrix at the pile head;

$437 \quad \mathfrak{R}_{\mathrm{h}}=$ horizontal impedance at the pile head;

$438\left[\mathfrak{R}_{x^{\prime}}\right]=$ normal impedance matrix at the pile head;

$439 \Theta_{\mathrm{a}}, \Theta_{\mathrm{b}}^{(j)}=$ rotation angle of a source pile; rotation of a receiver pile induced by the vibration of the 440 source pile in the $j$ direction; 
AFPS(Association Française du Génie Parasismique). (1990). "Association Franncaise de Genie Parasismique,

Recommendations", Presses del Ponts at Chausees, Paris.

CEN(European Committee for Standardization). (2004). " Design of Structures for Earthquake Resistance, Part 5: Foundations, Retaining Structures and Geotechnical Aspects." Eurocode 8, Brussels.

Deng, N., Kulesza, R., and Ostadan, F. (2007). "Seismic soil-pile group interaction analysis of a battered pile group." 4th Int. Conf. Earthq. Geotech. Eng., Aristotle University of Thessaloniki, Thessaloniki.

Dobry, R., and Gazetas, G. (1988). "Simple method for dynamic stiffness and damping of floating pile groups."

Gazetas, G., and Mylonakis, G. (1998). "Seismic soil-structure interaction: new evidence and emerging issues." Geotechnical earthquake engineering and soil dynamics III, Seattle, 1119-1174.

Gerolymos, N., Giannakou, A., Anastasopoulos, I., and Gazetas, G. (2008). "Evidence of beneficial role of inclined piles: observations and summary of numerical analyses." B. Earthq. Eng., 6(4), 705-722.

Gerolymos, N., and Gazetas, G. (2006). "Winkler model for lateral response of rigid caisson foundations in linear soil." Earthquake Eng. Struct. Dynam., 26(5), 347-361.

Ghasemzadeh, H., and Alibeikloo, M. (2011). "Pile - soil - pile interaction in pile groups with batter piles under dynamic loads." Soil Dyn. Earthq. Eng., 31(8), 1159-1170.

Ghazavi, M., Ravanshenas, P., and El Naggar, M. H. (2013). "Interaction between inclined pile groups subjected to harmonic vibrations." Soils Found., 53(6), 789-803.

Gotman, A. L. (2013). "Performance of combined pile foundations under a horizontal load." Soil mech. found. eng., 50(3), 85-91.

Kampitsis, A. E., Sapountzakis, E. J., Giannakos, S. K., and Gerolymos, N. A. (2013). "Seismic soil - pile - structure kinematic and inertial interaction-A new beam approach." Soil Dyn. Earthq. Eng., 55, 211-224.

Kaynia, A. M., and Kausel, E. (1982). Dynamic stiffness and seismic response of pile groups. Diss. Massachusetts Institute of technology, U.S.

Liu, Y., Wang, X., and Zhang, M. (2014). "Lateral Vibration of Pile Groups Partially Embedded in Layered Saturated Soils." International Journal of Geomechanics., 10.1061/(ASCE)GM.1943-5622.0000406, 04014063.

Makris, N., and Gazetas, G. (1992). "Dynamic pile-soil-pile interaction. Part II: Lateral and seismic response." Earthquake Eng. Struct. Dynam., 21(2), 145-162.

Medina, C., Padrón, L. A., Aznárez, J. J., Santana, A., and Maeso, O. (2014). "Kinematic interaction factors of deep foundations with inclined piles." Earthquake Eng. Struct. Dynam., 43(13), 2035-2050.

Medina, C., Padrón, L. A., Aznárez, J. J., and Maeso, O. (2015). "Influence of pile inclination angle on the dynamic properties and seismic response of piled structures." Soil Dyn. Earthq. Eng., 69, 196-206.

Mylonakis, G. (2001). "Elastodynamic model for large-diameter end-bearing shafts." Soils Found., 41(3), 31-44.

Mylonakis, G., and Gazetas, G. (1998). "Vertical vibration and additional distress of grouped piles in layered soil." Soils Found., 38(1), 1-14.

Mylonakis, G., and Gazetas, G. (1999). "Lateral vibration and internal forces of grouped piles in layered soil." J. Geotech. Geoenviron., 125(1), 16-25.

Novak, M., and Aboul-Ella, F. (1978). "Impedance functions of piles in layered media." J. Eng. Mech. Div., 104(3), 643-661.

Novak, M., and Sachs, K. (1973). "Torsional and coupled vibrations of embedded footings." Earthquake Eng. Struct. Dynam., 2(1), 11-33. 
Okawa, K., Kamei, H., Kimura, M., and Zhang, F. (2002). "Dynamic behaviour of a group-pile foundation with inclined piles in loose sand." Phy modelling in geotech: ICPMG 02, 729-734.

487 Padrón, L. A., Aznárez, J. J., Maeso, O., and Saitoh, M. (2012). "Impedance functions of end-bearing inclined piles." Soil 488 Dyn. Earthq. Eng., 38, 97-108.

489 Padrón, L. A., Aznárez, J. J., Maeso, O., and Santana, A. (2010). "Dynamic stiffness of deep foundations with inclined 490 piles." Earthquake Eng. Struct. Dynam., 39, 1343 - 1367.

491 Poulos, H. G. (2006). "Raked Piles—Virtues and Drawbacks." J. Geotech. Geoenviron., 132(6), 795 - 803.

492 Poulos, H. G., and Davis, E. H. (1980). Pile foundation analysis and design, Wiley, New York, U.S.

493 Sadek, M., and Isam, S. (2004). "Three-dimensional finite element analysis of the seismic behavior of inclined 494 micropiles." Soil Dyn. Earthq. Eng., 24(6), 473-485.

495 Saitoh, M., Padron, L. A., Aznarez, J. J., Maeso, O., \& Goit, C. S. (2016). "Expanded superposition method for 496 impedance functions of inclined-pile groups." Int. J. Numer. Anal. Met., 40(2), 185-206.

497 Sica, S., Mylonakis, G., and Simonelli, A. L. (2011). "Transient kinematic pile bending in two-layer soil." Soil Dyn. 498 Earthq. Eng., 31(7), 891-905.

499 Turan, A., Hafez, D., and El Naggar, M. H. (2013). "The performance of inclined secant micro-pile walls as active 500 vibration barriers." Soil Dyn. Earthq. Eng., 55, 225-232.

501 Wang, J., Lo, S. H., and Zhou, D. (2014). "Effect of a forced harmonic vibration pile to its adjacent pile in layered elastic 502 soil with double-shear model." Soil Dyn. Earthq. Eng., 67, 54-65.

503 Wang, J., Zhou, D., and Liu, W. Q. (2014). "Horizontal Impedance of Pile Groups Considering Shear Behavior of 504 Multilayered Soils." Soils Found., 54(5), 927-937. 


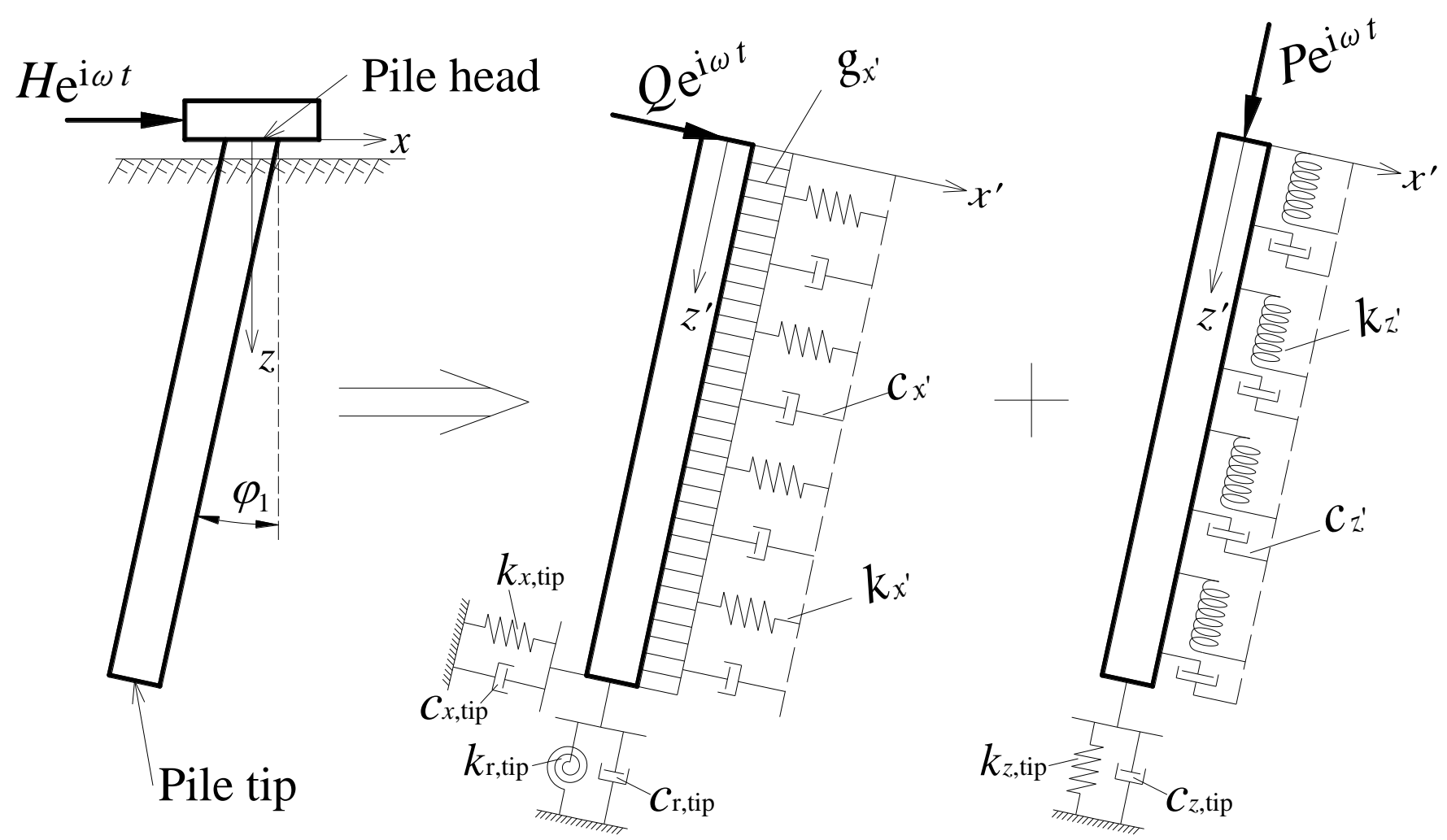

Fig. 1 T-P model for inclined pile-soil dynamic interaction 


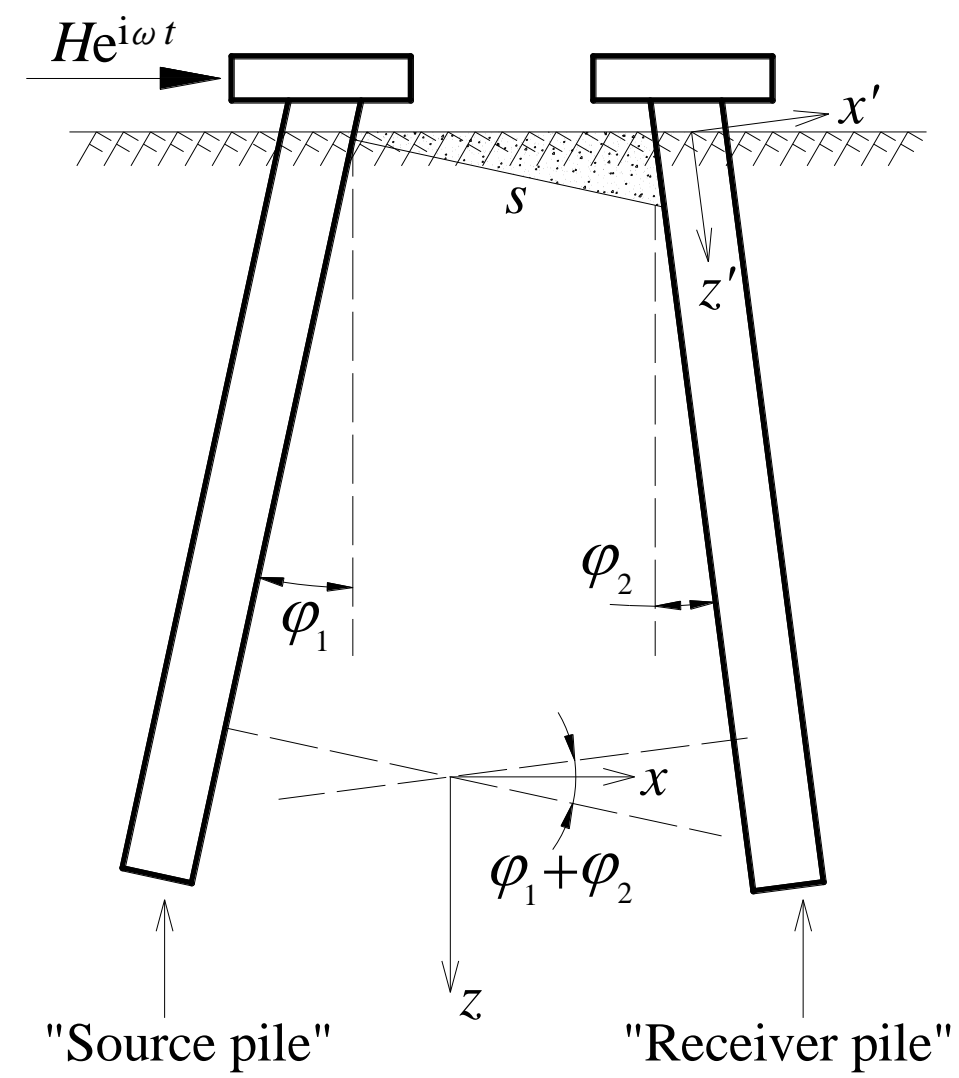

(a)

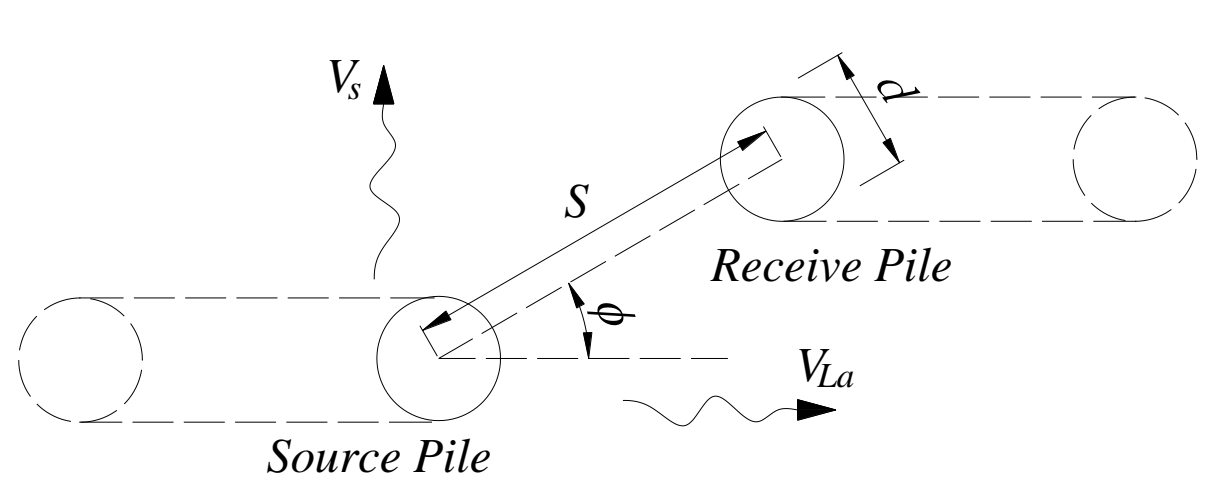

(b)

Fig. 2 Dynamic interaction between two adjacent inclined piles subjected to a horizontal harmonic force (a: Sectional view of adjacent inclined piles; b: Plane view of adjacent inclined piles) 


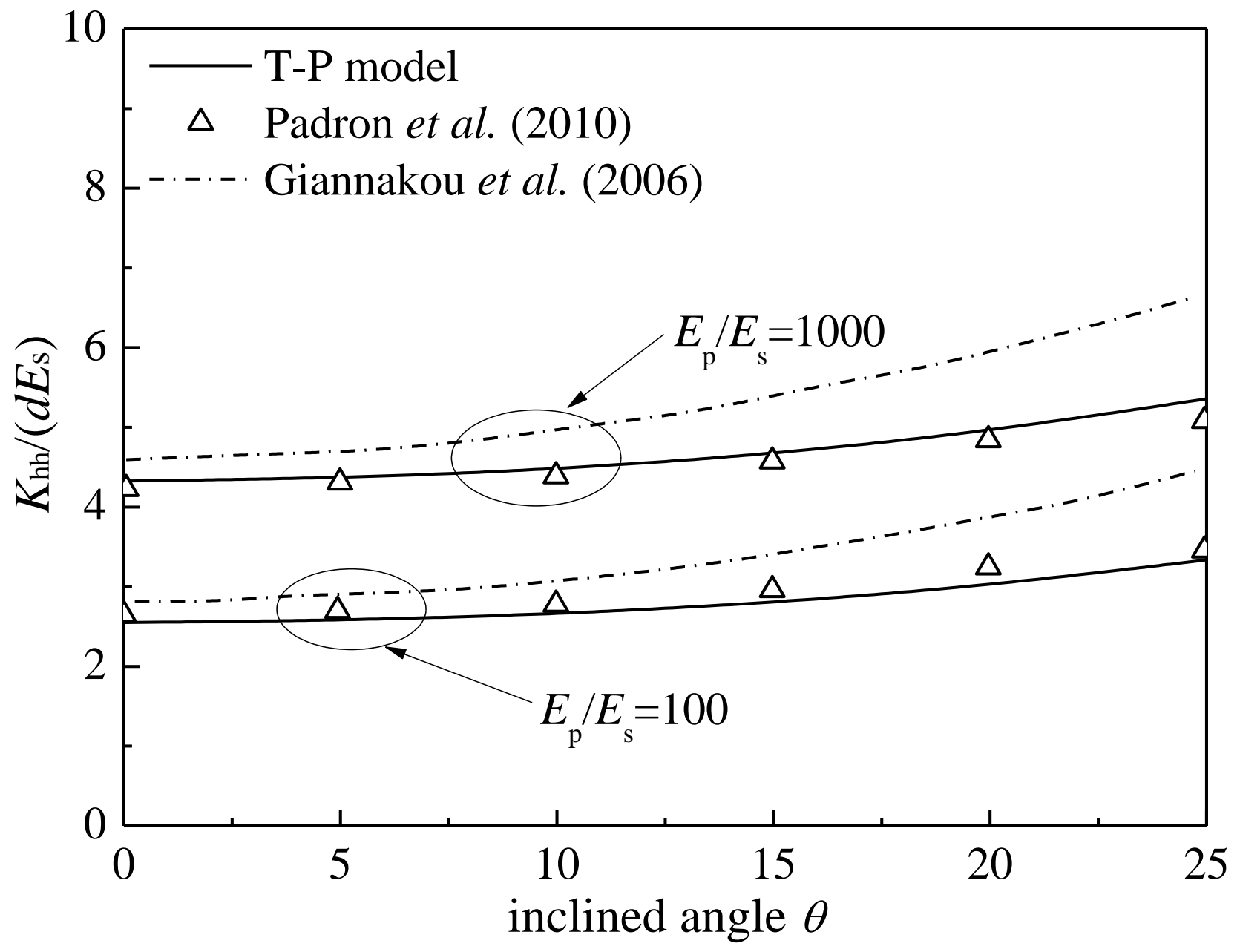

Fig. 3 Comparison of T-P model and numerical models for static stiffness of inclined pile $\left(L / d=15, \rho_{\mathrm{s}} / \rho_{\mathrm{p}}=0.7, v_{\mathrm{s}}=0.4, \beta_{\mathrm{s}}=0.05\right)$ 

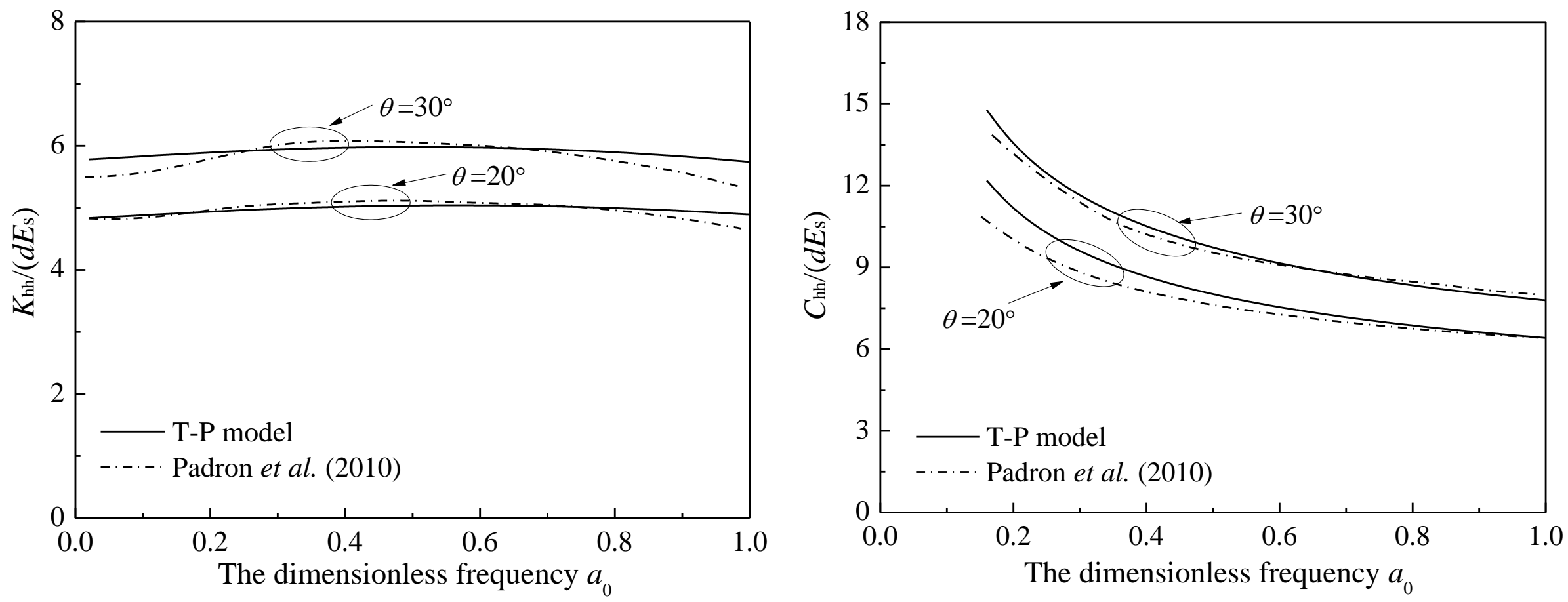

Fig. 4 Comparison of T-P model and BEM-FEM model for horizontal impedance of inclined pile $\left(E_{\mathrm{p}} / E_{\mathrm{s}}=1000, L / d=15, \rho_{\mathrm{s}} / \rho_{\mathrm{p}}=0.7, v_{\mathrm{s}}=0.4, \beta_{\mathrm{s}}=0.05\right)$ 

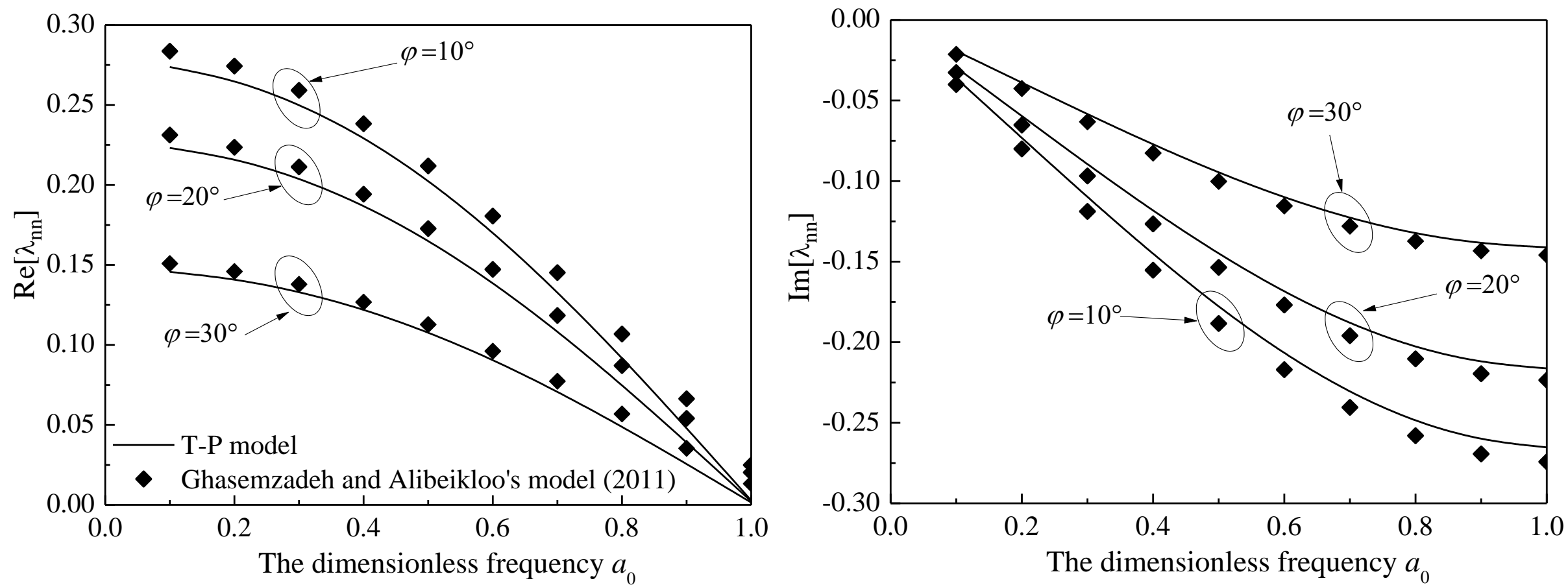

Fig. 5 Comparison of the normal-normal interaction factors for different inclined angles $\left(E_{\mathrm{p}} / E_{\mathrm{s}}=1000, L / d=25, \rho_{\mathrm{s}} / \rho_{\mathrm{p}}=0.7, v_{\mathrm{s}}=0.4, \beta_{\mathrm{s}}=0.05, s / d=3\right)$ 

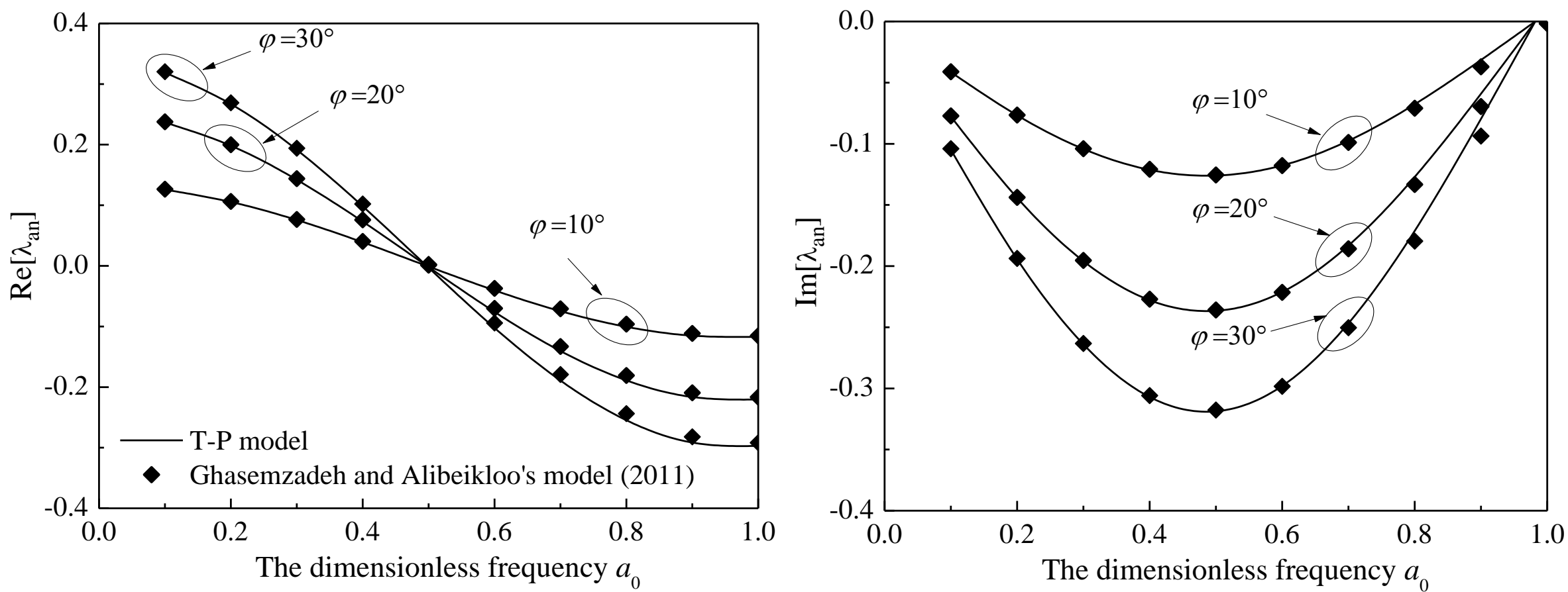

Fig. 6 Comparison of the axial-normal interaction factors for different inclined angles $\left(E_{\mathrm{p}} / E_{\mathrm{s}}=1000, L / d=25, \rho_{\mathrm{s}} / \rho_{\mathrm{p}}=0.7, v_{\mathrm{s}}=0.4, \beta_{\mathrm{s}}=0.05, s / d=3\right)$ 

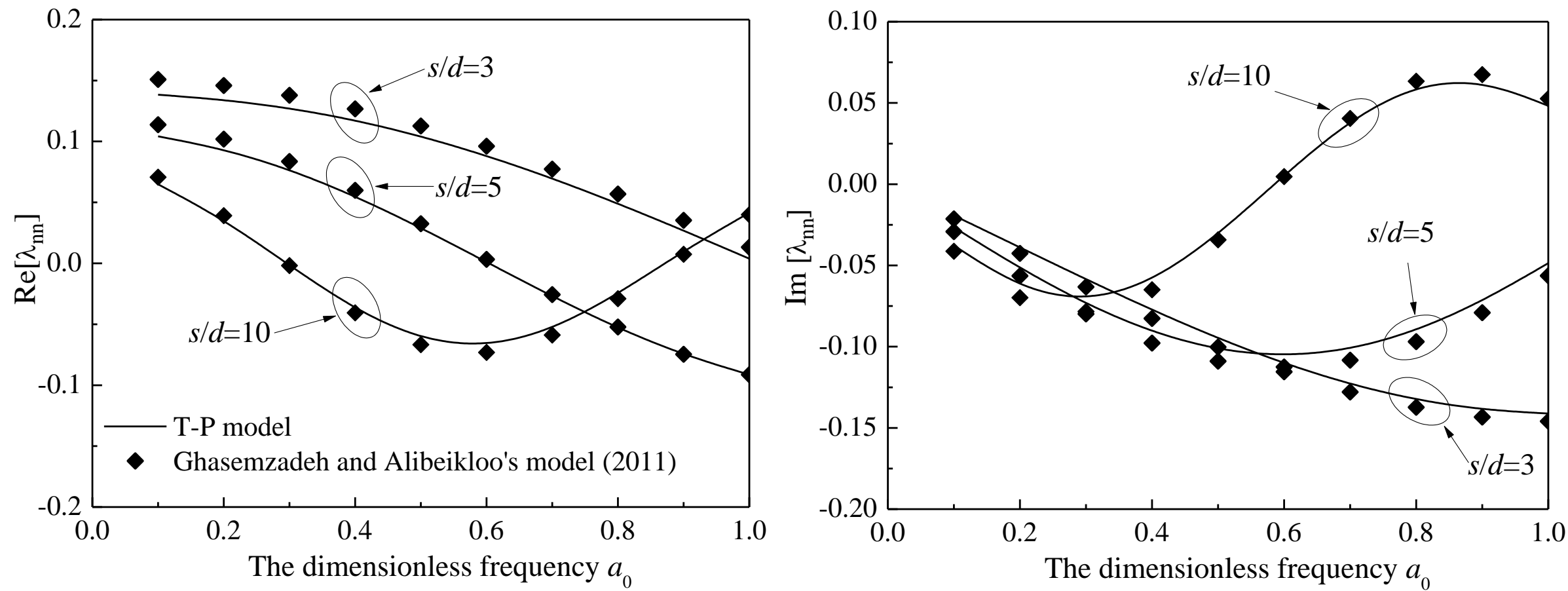

Fig. 7 Comparison of normal-normal interaction factors for different distance-diameter ratios

$\left(E_{\mathrm{p}} / E_{\mathrm{s}}=1000, L / d=25, \rho_{\mathrm{s}} / \rho_{\mathrm{p}}=0.7, v_{\mathrm{s}}=0.4, \beta_{\mathrm{s}}=0.05, \varphi_{1}=\varphi_{2}=30^{\circ}\right)$ 

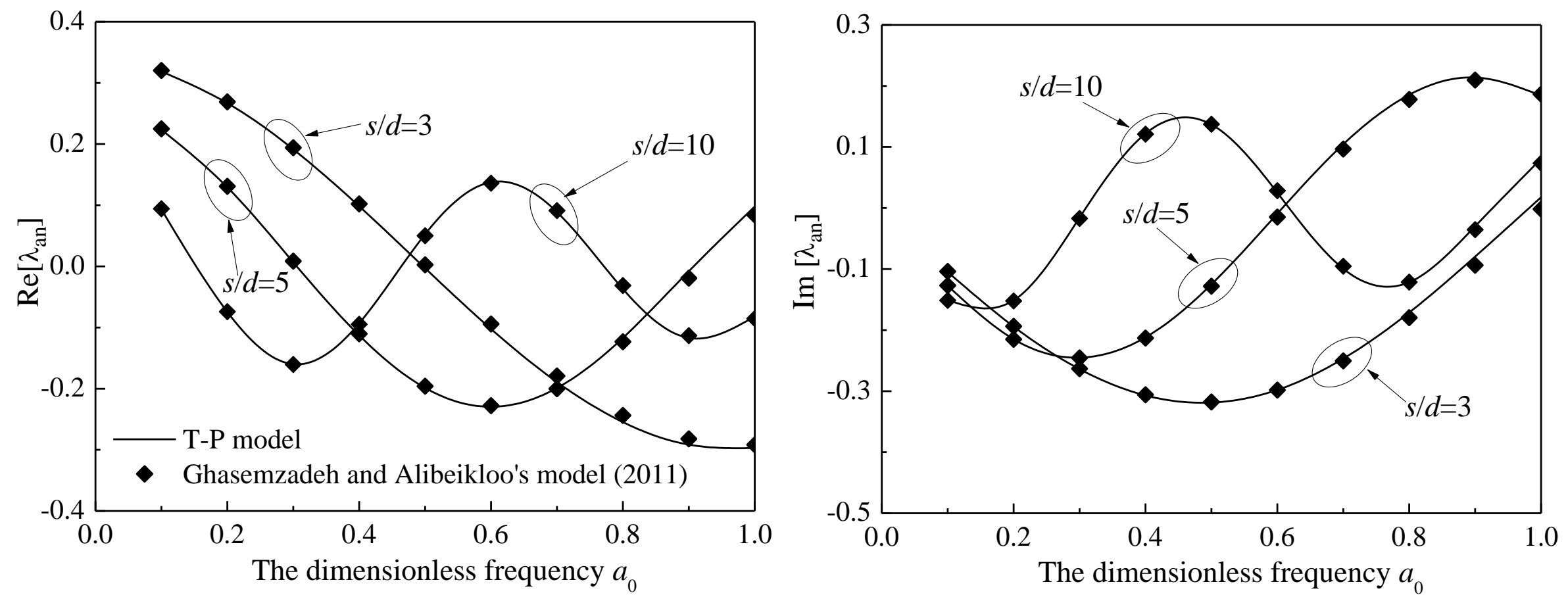

Fig. 8 Comparison of axial-normal interaction factors for different distance-diameter ratios $\left(E_{\mathrm{p}} / E_{\mathrm{s}}=1000, L / d=25, \rho_{\mathrm{s}} / \rho_{\mathrm{p}}=0.7, v_{\mathrm{s}}=0.4, \beta_{\mathrm{s}}=0.05, \varphi_{1}=\varphi_{2}=30^{\circ}\right)$ 

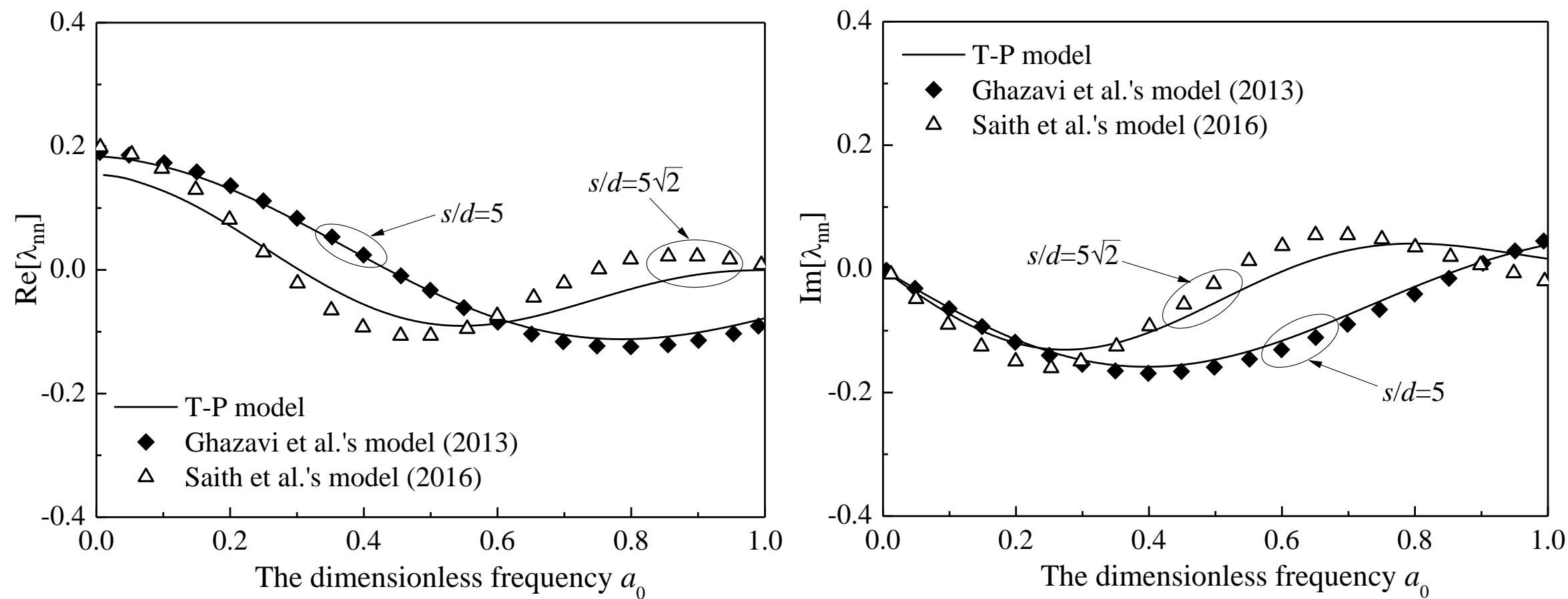

Fig. 9 Comparison of normal -normal interaction factors for different models

$\left(E_{\mathrm{p}} / E_{\mathrm{s}}=1000, L / d=15, \rho_{\mathrm{s}} / \rho_{\mathrm{p}}=0.7, v_{\mathrm{s}}=0.4, \beta_{\mathrm{s}}=0.05, \varphi_{1}=\varphi_{2}=20^{\circ}\right)$ 


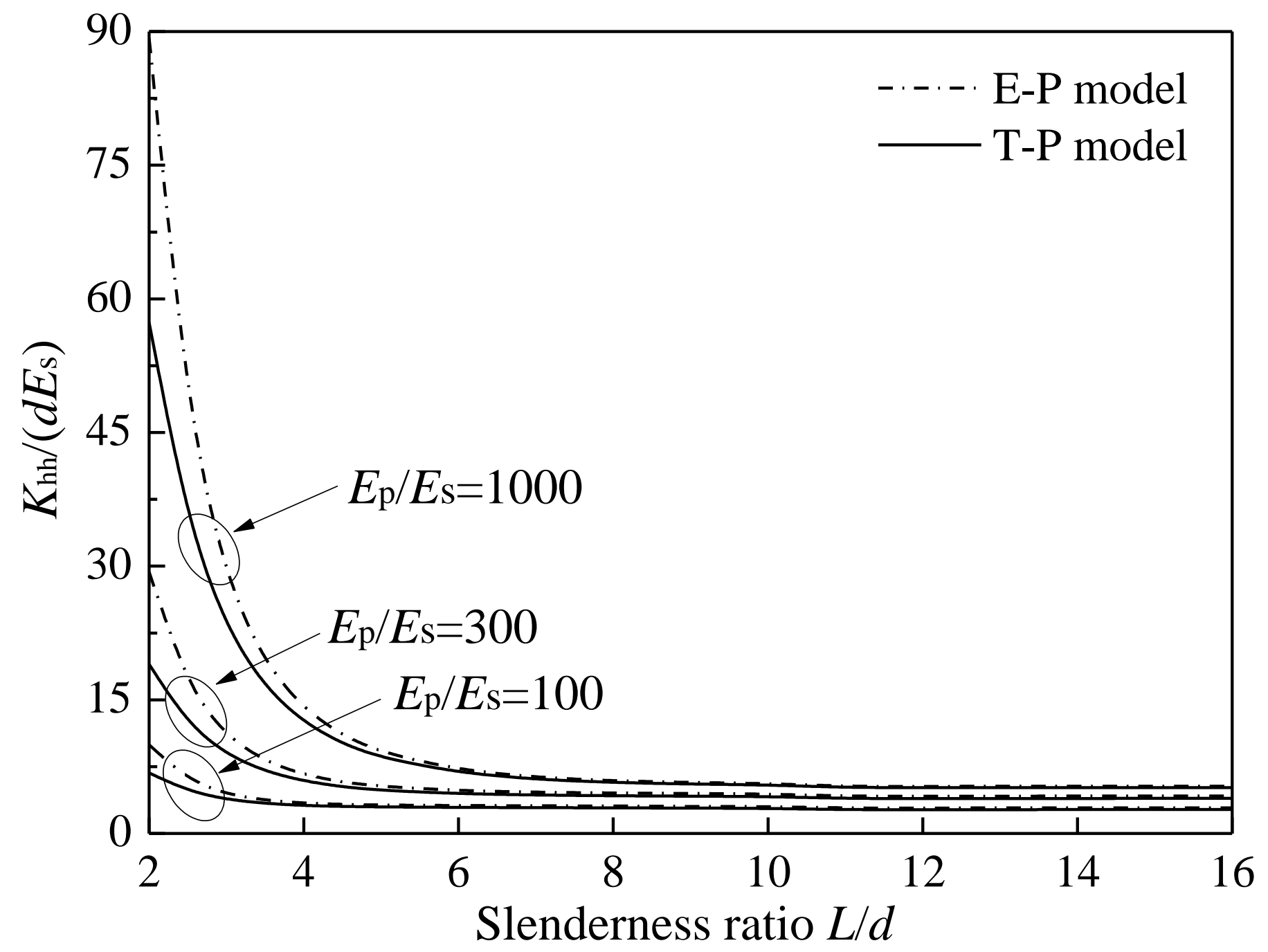

Fig. 10 Variation of stiffness with slenderness ratio for different models

$\left(\rho_{\mathrm{s}} / \rho_{\mathrm{p}}=0.7, v_{\mathrm{s}}=0.4, \beta_{\mathrm{s}}=0.05, \varphi=20^{\circ}\right)$ 

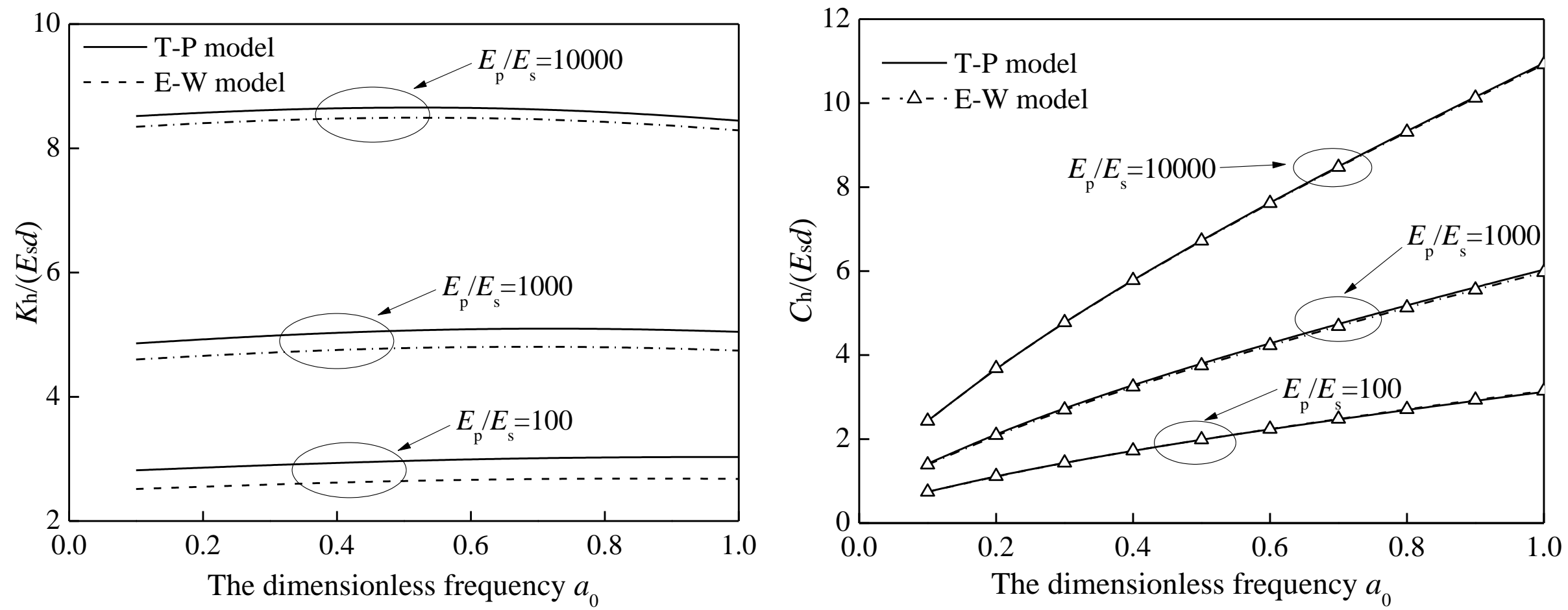

Fig. 11 Shear effect of soil on horizontal impedance of an inclined pile for different pile-soil elastic modulus ratios $E_{\mathrm{p}} / E_{\mathrm{s}}$ $\left(L / d=15, \rho_{\mathrm{s}} / \rho_{\mathrm{p}}=0.7, v_{\mathrm{s}}=0.4, \beta_{\mathrm{s}}=0.05, \varphi=15^{\circ}\right)$ 

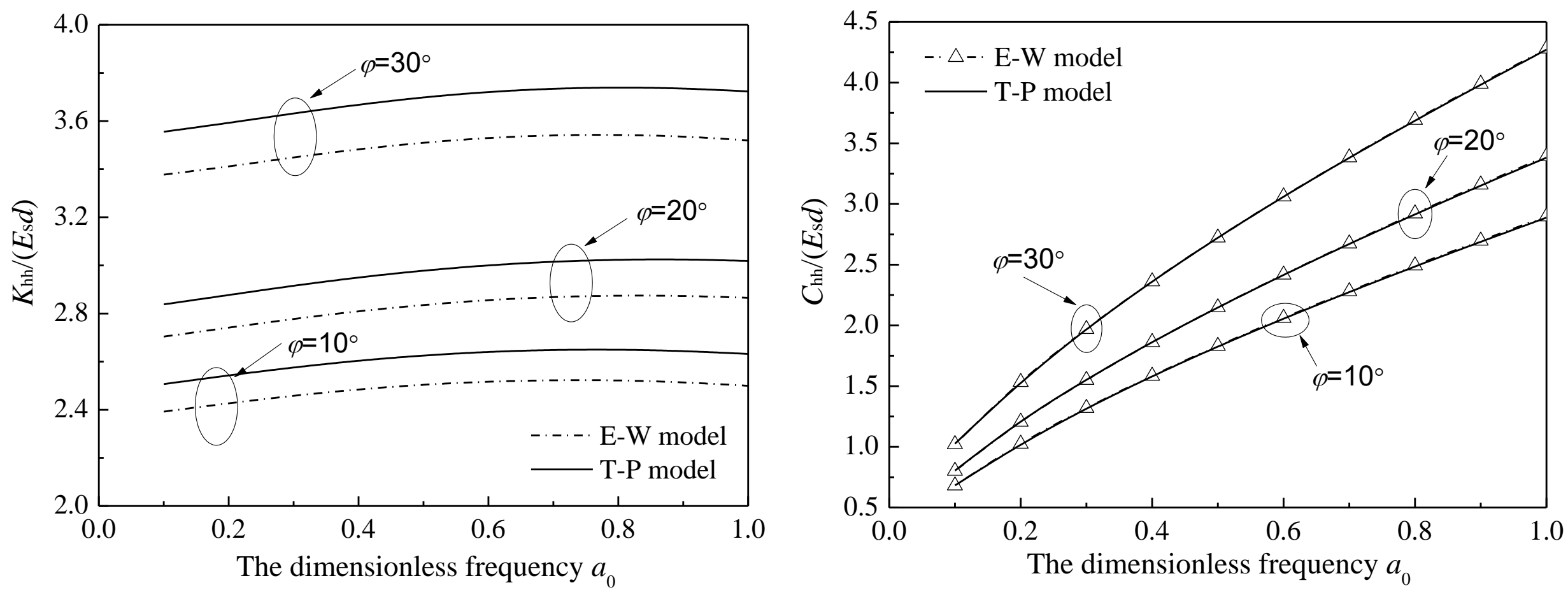

Fig. 12 Shear effect of soil on the impedance of an inclined pile for different inclined angles

$\left(E_{\mathrm{p}} / E_{\mathrm{s}}=100, L / d=15, \rho_{\mathrm{s}} / \rho_{\mathrm{p}}=0.7, v_{\mathrm{s}}=0.4, \beta_{\mathrm{s}}=0.05\right)$ 

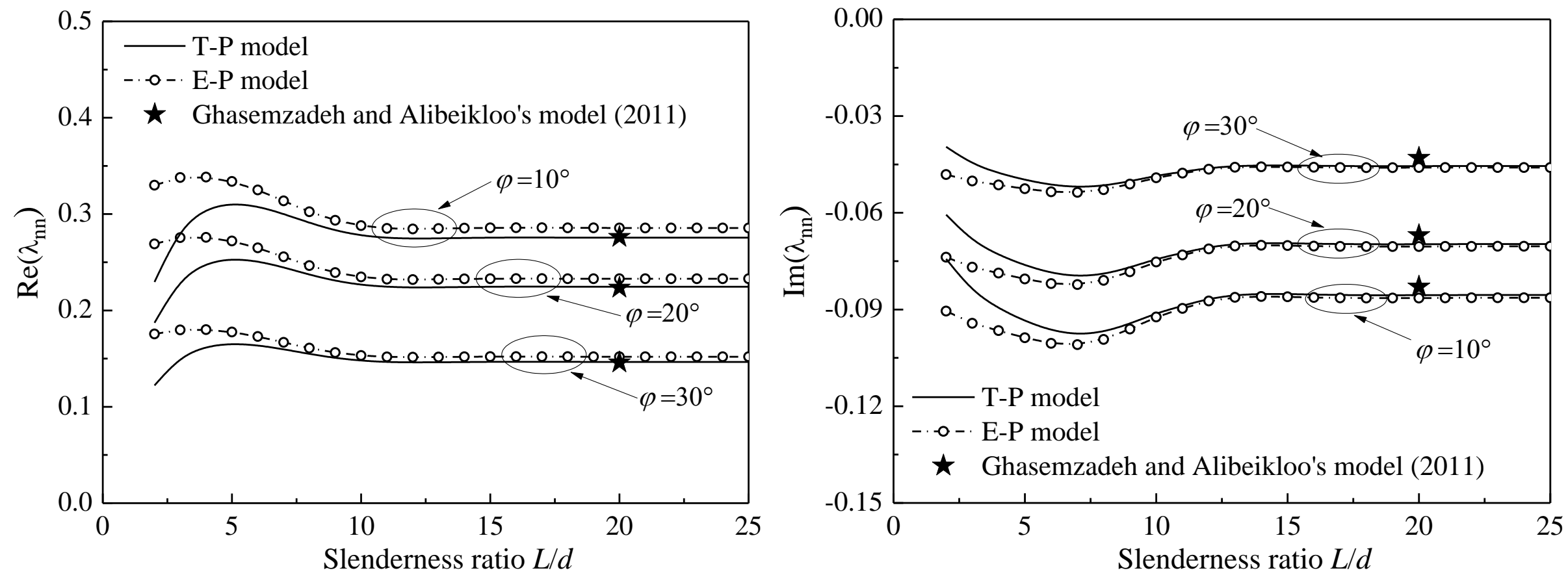

Fig.13 Variation of normal-normal interaction factor with the slenderness ratio for different models $\left(E_{\mathrm{p}} / E_{\mathrm{s}}=1000, \rho_{\mathrm{s}} / \rho_{\mathrm{p}}=0.7, v_{\mathrm{s}}=0.4, \beta_{\mathrm{s}}=0.05, s / d=3, a_{0}=0.2\right)$ 

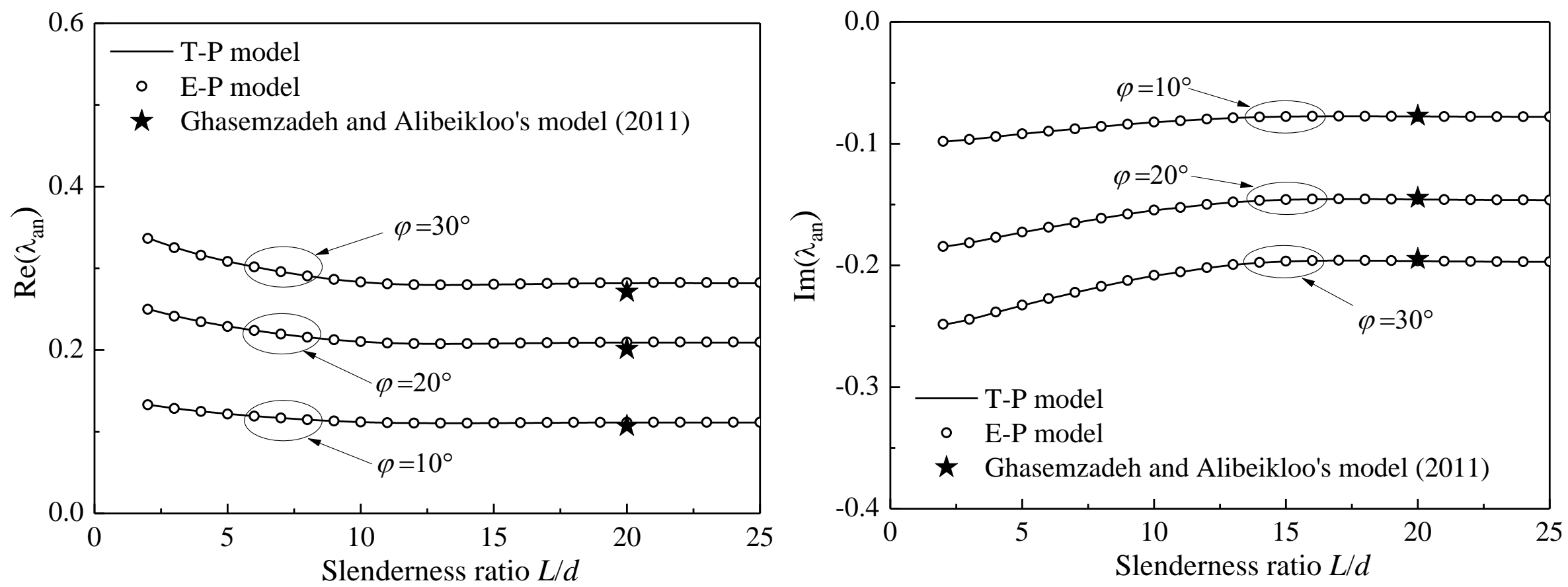

Fig.14 Variation of axial-normal interaction factor with the slenderness ratio for different models $\left(E_{\mathrm{p}} / E_{\mathrm{s}}=1000, \rho_{\mathrm{s}} / \rho_{\mathrm{p}}=0.7, v_{\mathrm{s}}=0.4, \beta_{\mathrm{s}}=0.05, s / d=3, a_{0}=0.2\right)$ 

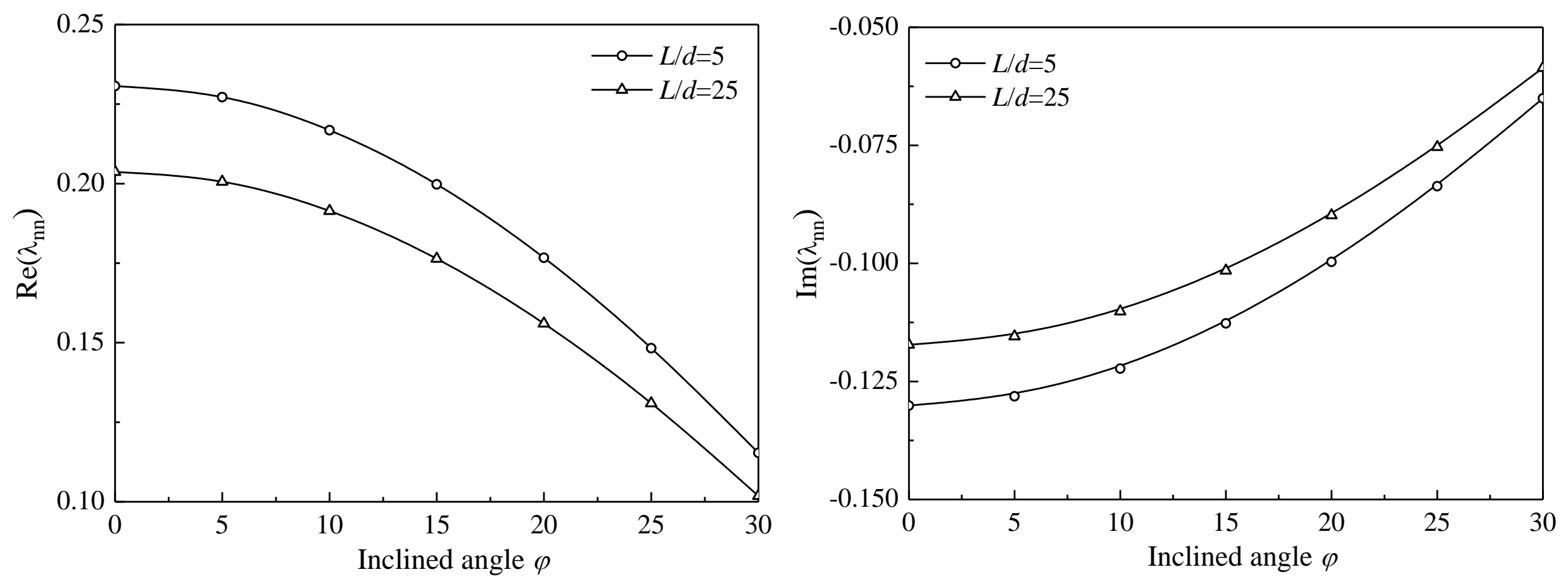

Fig. 15 Variation of normal-normal interaction factor with inclined angle for different slenderness ratios $\left(E_{\mathrm{p}} / E_{\mathrm{s}}=1000, \rho_{\mathrm{s}} / \rho_{\mathrm{p}}=0.7, v_{\mathrm{s}}=0.4, \beta_{\mathrm{s}}=0.05, s / d=3, a_{0}=0.2\right)$ 

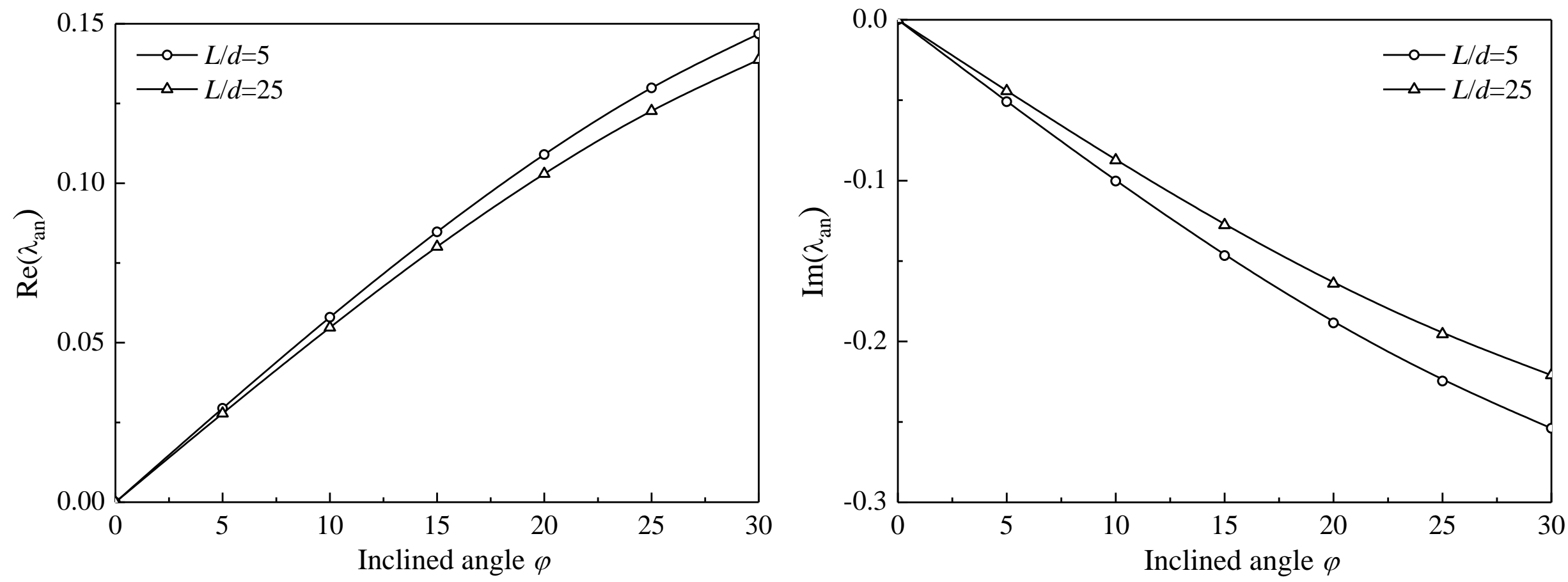

Fig. 16 Variation of axial-normal interaction factor with inclined angle for different slenderness ratios $\left(E_{\mathrm{p}} / E_{\mathrm{s}}=1000, \rho_{\mathrm{s}} / \rho_{\mathrm{p}}=0.7, v_{\mathrm{s}}=0.4, \beta_{\mathrm{s}}=0.05, s / d=3, a_{0}=0.2\right)$ 
Table 1. Effects of shear deformation and inclined angles on the normalized stiffness $K_{\mathrm{h}} /\left(E_{\mathrm{s}} d\right)$ at the head

\begin{tabular}{|c|c|c|c|c|c|c|c|c|c|c|}
\hline \multirow{2}{*}{\multicolumn{2}{|c|}{ Inclined angle }} & \multicolumn{3}{|c|}{$E_{\mathrm{p}} / E_{\mathrm{s}}=100$} & \multicolumn{3}{|c|}{$E_{\mathrm{p}} / E_{\mathrm{s}}=300$} & \multicolumn{3}{|c|}{$E_{\mathrm{p}} / E_{\mathrm{s}}=1000$} \\
\hline & & $L / d=5$ & $L / d=7$ & $L / d=10$ & $L / d=5$ & $L / d=7$ & $L / d=10$ & $L / d=5$ & $L / d=7$ & $L / d=10$ \\
\hline \multirow{2}{*}{$0^{\circ}$} & $\begin{array}{c}\text { Mylonakis } \\
(2001)\end{array}$ & 2.85 & 2.59 & 2.35 & 3.58 & 3.40 & 3.10 & 4.69 & 4.38 & 4.18 \\
\hline & $\begin{array}{c}\text { Prestent } \\
\text { Error }\end{array}$ & $\begin{array}{c}2.594 \\
(\mathbf{8 . 9 7 \% )} \\
\end{array}$ & $\begin{array}{c}2.512 \\
(\mathbf{3 . 0 0 \%}) \\
\end{array}$ & $\begin{array}{c}2.296 \\
(\mathbf{2 . 2 8 \%}) \\
\end{array}$ & $\begin{array}{c}3.634 \\
(\mathbf{1 . 5 0 \%}) \\
\end{array}$ & $\begin{array}{c}3.391 \\
(\mathbf{0 . 2 5 \%}) \\
\end{array}$ & $\begin{array}{c}3.095 \\
(\mathbf{0 . 1 5 \%}) \\
\end{array}$ & $\begin{array}{c}6.274 \\
(\mathbf{3 3 . 7 8 \%}) \\
\end{array}$ & $\begin{array}{c}4.829 \\
(\mathbf{1 0 . 2 4 \% )}\end{array}$ & $\begin{array}{c}4.244 \\
(\mathbf{1 . 5 4 \% )} \\
\end{array}$ \\
\hline $10^{\circ}$ & Prestent & 2.696 & 2.608 & 2.387 & 3.877 & 3.513 & 3.205 & 7.146 & 5.102 & 4.387 \\
\hline
\end{tabular}

Note: the calculation parameters: $v_{\mathrm{s}}=0.40 ; v_{\mathrm{p}}=0.30 ; \rho_{\mathrm{s}} / \rho_{\mathrm{p}}=0.8 ; a_{0}=0.001$. 